\title{
Tachykinins and Calcitonin Gene-Related Peptide Enhance Release of Endogenous Glutamate and Aspartate from the Rat Spinal Dorsal Horn Slice
}

\author{
I. Kangrga and $\mathbf{M}$. Randic \\ Department of Veterinary Physiology and Pharmacology, lowa State University, Ames, lowa 50011
}

The effects of dorsal root stimulation and of substance $P$ (SP), neurokinin A (NKA), and calcitonin gene-related peptide (CGRP) on the basal release of 9 endogenous amino acids, including glutamate (Glu) and aspartate (Asp), have been investigated using the rat spinal cord slice-dorsal root ganglion preparation and high-performance liquid chromatography with fluorimetric detection. High-intensity repetitive electrical stimulation of a lumbar dorsal root produced a $\mathrm{Ca}^{2+}$-dependent increase in the basal release of Asp, Glu, glycine (Gly), serine (Ser), and threonine (Thr). Low concentrations of SP $\left(2 \times 10^{-7} \mathrm{M}\right)$ caused a selective increase in the rate of basal release of Glu, whereas higher concentrations (1-5 $\times 10^{-6} \mathrm{M}$ ) produced, in addition, an increase in the basal release of Asp. The SP-induced increase of Glu persisted in the absence of external $\mathrm{Ca}^{2+}$, but the effect was blocked by (D-Arg', D-Pro', D-Trp ${ }^{7,9}$, Leu ${ }^{11}$ )-SP, an SP analog claimed to be an antagonist of the synthetic SP. NKA (5 $\times$ $10^{-7}-10^{-6} \mathrm{M}$ ), a related tachykinin coexpressed with SP in primary sensory neurons, enhanced the basal release of Gly. CGRP $\left(10^{-7} \mathrm{M}\right)$ caused a significant, largely $\mathrm{Ca}^{2+}$-independent increase in the basal release of Glu and Asp and a decrease in asparagine. SP and CGRP potentiated the electrically evoked release of Glu and Asp. Neonatal capsaicin treatment did not significantly alter the basal efflux of 9 endogenous amino acids from the spinal slices, but it prevented the dorsal root stimulation-evoked release of Asp, Glu, Gly, and Thr and the SP-induced increase in the basal release of Glu. However, the effect of CGRP was not significantly modified by the capsaicin treatment. These results indicate that tachykinins (SP and NKA) and CGRP are capable of modulating the basal and electrically evoked release of endogenous Glu and Asp, and these actions may provide an important mechanism by which the peptides contribute to the regulation of the primary afferent synaptic transmission. The enhancement of the basal and the dorsal root stimulation-evoked release of Glu and Asp by tachykinins and CGRP may have important physiological implications for strengthening the synaptic connections in the spinal dorsal horn.

\footnotetext{
Received Oct. 23, 1989; revised Jan. 5, 1990; accepted Jan. 8, 1990.

We wish to thank Drs. J. S. A. Larew, V. Miletic, and G. Pavlakovic for their help and critical comments. Support was provided by grants from USPHS (NS 26352), NSF (BNS 8418042), and the USA Department of Agriculture.

Correspondence should be addressed to $\mathrm{M}$. Randic at the above address.

Copyright (C) 1990 Society for Neuroscience $0270-6474 / 90 / 062026-13 \$ 02.00 / 0$
}

Immunohistochemical techniques have demonstrated that neurons contain multiple chemical substances that may act as neurotransmitters or neuromodulators. However, the physiological significance of this phenomenon, especially for information transfer in the nervous system, is not well understood.

Synaptic transmitters released during activation of primary sensory neurons in the dorsal horn of the rat spinal cord may elicit both fast and slow excitatory responses in a single neuron (Murase and Randic, 1984; Urban and Randic, 1984). Dicarboxylic amino acids, glutamate (Glu) and aspartate (Asp), appear to be the major candidates for the fast excitatory neurotransmitters in the mammalian CNS (Watkins and Evans, 1981; Mayer and Westbrook, 1987), including the spinal dorsal horn (Galindo et al., 1967; Salt and Hill, 1983; Kangrga et al., 1988; Gerber and Randic, 1989a). Tachykinins, substance P (SP) and neurokinin A (NKA), and calcitonin gene-related peptide (CGRP) appear to be functionally involved in the slow primary afferent synaptic transmission (Urban and Randic, 1984; Randic et al., 1986; Ryu et al., 1988a; Gerber and Randic, 1989b).

Immunocytochemical studies have shown that about $70 \%$ of both large and small DRG neurons are labeled for Glu (Wanaka et al., 1987), and Glu immunoreactivity has been detected within myelinated and unmyelinated primary afferent terminals in the superficial dorsal horn (Weinberg et al., 1987; Westlund et al., 1989a). $\mathrm{Ca}^{2+}$-dependent release of Glu from electrically activated primary afferent fibers has been demonstrated (Roberts and Mitchell, 1972; Roberts, 1974; Takeuchi et al., 1983; Kawagoe et al., 1986). L-Glu binding sites are found in high densities in the superficial laminae of the rat spinal dorsal horn (Greenamyre et al., 1984; Monaghan and Cotman, 1985). Glu was found to excite and depolarize almost all spinal dorsal horn neurons in vivo (Curtis et al., 1960; Watkins and Evans, 1981) and a proportion of dorsal horn neurons in vitro (Zieglgänsberger and Puil, 1973; Schneider and Perl, 1985).

SP and NKA are also present in a proportion of small DRG neurons and in numerous terminals in the superficial laminae of the spinal dorsal horn (Hökfelt et al., 1975; Barber et al., 1979; Kanazawa et al., 1984; Dalsgaard et al., 1985). On electrical or chemical stimulation, $\mathrm{Ca}^{2+}$-dependent release of SP and NKA from activated primary afferent fibers has been demonstrated both in vitro (Otsuka and Konishi, 1976; Gamse et al., 1979; Hua et al., 1986) and in vivo (Yaksh et al., 1980; Brodin et al., 1987). SP binding sites have been demonstrated autoradiographically in the spinal dorsal horn (Mantyh et al., 1984a), and a correlation has been observed between the distribution of ${ }^{3} \mathrm{H}-\mathrm{SP}$ binding sites and the ability of SP to stimulate phosphatidylinositol turnover (Mantyh et al., 1984b). SP depolarizes 
dorsal horn neurons (Henry et al., 1975; Randic and Miletic, 1977).

The presence of CGRP-like immunoreactivity (CGRP-LI) in rat DRG neurons and the spinal dorsal horn has been demonstrated (Gibson et al., 1984). Both CGRP binding sites (Henke et al., 1985) and CGRP-LI (Gibson et al., 1984) exist in high concentrations in the superficial layers of the spinal dorsal horn. Release of CGRP from rat primary sensory neurons in response to capsaicin (Franco-Cereceda et al., 1987; Diez Guerra et al., 1988) and electrical stimulation (Saria et al., 1986) has been shown.

There is evidence that SP, NKA, and CGRP may modulate primary afferent neurotransmission by acting both at presynaptic (Kawagoe et al., 1986; Ryu et al., 1988a, b; Kangrga et al., 1989a, b) and postsynaptic sites (Murase and Randic, 1984; Murase et al., 1989a, b). Although the coexistence of SP and Glu in some small primary afferent neurons (Battaglia et al., 1987) and their terminals in the superficial dorsal horn (DeBiasi and Rustioni, 1988), and the coexistence of SP, NKA, and CGRP in a proportion of capsaicin-sensitive DRG neurons (Nagy et al., 1981; Gibson et al., 1984; Franco-Cereceda et al., 1987; Diez Guerra et al., 1988) has been reported, our understanding of physiological implications of this phenomenon is still unclear. An important, but as yet not systematically investigated site at which coexistent peptides could modulate excitatory amino acid function, and in this way contribute to primary afferent synaptic transmission, is found presynaptically in the control of basal and dcpolarization-evoked release of Glu and Asp. In an attempt to determine whether SP, NKA, and CGRP modulate the release pattern of excitatory amino acids, we have investigated the efflux of 9 endogenous amino acids, including Glu and Asp, from the superfused spinal cord slices of the rat in response to electrical stimulation of dorsal roots, administration of neuropeptides (SP, NKA, and CGRP), and chronic treatment of rats with capsaicin. Preliminary reports of some aspects of this work have been published (Kangrga et al., 1989a, b).

\section{Materials and Methods}

Horizontal slices were obtained from Sprague-Dawley rats of both sexes (23-45 d old) by using a technique that has been described in detail elsewhere (Murase and Randic, 1983; Gerber et al., 1989). Bricfly, aftcr the animal was anesthetized with ether, a segment of the lumbosacral (L5-S1) spinal cord was dissected out and sectioned along the longitudinal axis with a Vibratome to yield one $300-400-\mu \mathrm{m}$-thick horizontal slice with dorsal rootlets and dorsal root ganglia attached. In some experiments, a part of the sciatic nerve was left in contact with a dorsal root ganglion. The slice was incubated for $1 \mathrm{hr}$ in oxygenated $\left(95 \% \mathrm{O}_{2}\right.$ $+5 \% \mathrm{CO}_{2}$ ) control solution (in mM): $\mathrm{NaCl}, 124 ; \mathrm{KCl}, 5 ; \mathrm{KH}_{2} \mathrm{PO}_{4}, 1.2$; $\mathrm{CaCl}_{2}, 2.4 ; \mathrm{MgSO}_{4}, 1.3 ; \mathrm{NaHCO}_{3}, 26$; glucose, $10 ; \mathrm{pH} 7.4$ at $30 \pm 1^{\circ} \mathrm{C}$. The use of a high- $\mathrm{K}^{+}$solution during cutting and incubation of the slices seemed to improve their viability as assessed electrophysiologically in the same preparation. After the incubation, a slice was placed in one compartment of the 2-compartment chamber and perfused with oxygenated modified Krebs solution (containing $1.9 \mathrm{~mm} \mathrm{KCl}$, all other salts were unchanged) at $0.5 \mathrm{ml} / \mathrm{min}$. The dorsal roots and dorsal root ganglia were placed into the second compartment and immersed under the mineral oil. Lubriseal (Thomas Scientific) was used to ensure a leakproof and electrical isolation between the 2 compartments. A lumbar dorsal rootlet was placed on the 2 pairs of bipolar platinum electrodes: the distal pair was used for electrical stimulation of primary afferent fibers and the proximal pair for recording the compound action potentials. The stimulation parameters were selected to activate both low-threshold, fast-conducting myelinated fibers $(A \beta)$ and the high-threshold, slower-conducting myelinated $(A \delta)$ and unmyelinated $(C)$ fibers $(25-30 \mathrm{~V}$, $0.02-1.0 \mathrm{msec}$ at $3-10 \mathrm{~Hz}$ ). The compound action potentials were mon- itored throughout the periods of stimulation and stored on diskettes of a digital oscilloscope (Nicolet, model 4092). Samples of perfusate $(0.5$ $\mathrm{ml}$ ) were collected at regular 3-10 min intervals before, during, and after stimulation of the dorsal roots or application of tachykinins and CGRP. Samples were kept frozen at $-80^{\circ} \mathrm{C}$ until derivatization and chemical analysis. Quantification of 9 endogenous amino acids contained in the spinal perfusate was achieved by reversed-phase highperformance liquid chromatography (HPLC) with fluorimetric detection following precolumn derivatization with $O$-phthaldialdehyde (OPA) 2-mercaptoethanol reagent (Lindroth and Mopper, 1979). OPA 2-mercaptoethanol derivatives were produced by taking $25 \mu$ l OPA reagent solution and mixing with $25 \mu \mathrm{l}$ amino acid mixture (standards or sample). After $1 \mathrm{~min}, 150 \mu \mathrm{l}$ of the mixture was injected onto the chromatographic column for analysis. Hydroxylysine $(30 \mu \mathrm{M})$ was added to each sample as an internal standard and/or reference injections of amino acid standards were injected periodically. Chromatography was performed on a $15 \mathrm{~cm}$. Adsorbasphere-OPA-HR column (Alltech Associates) using a pH 5.9 sodium acetate-tetrahydrofuran/methanol gradient. Fluorescence was detected with a Kratos FS 950 fluorimeter. The amino acids measured came off the column in the following order: Asp, Glu, asparagine (Asn), serine (Ser), glutamine (Gln), glycine (Gly), threonine (Thr), alanine (Ala), and GABA followed by hydroxylysine. Results reported arc the avcrages of duplicate runs with each run lasting $31 \mathrm{~min}$. SP $\left(10^{-7}-5 \times 10^{-6} \mathrm{M}\right.$, Cambridge Research Biochemicals, CRB $)$, NKA $\left(5 \times 10^{-7}-10^{-6} \mathrm{M}, \mathrm{CRB}\right)$, and rat CGRP $\left(10^{-8}-10^{-6} \mathrm{M}, \mathrm{CRB}\right)$ were applied into the slice perfusate for $5 \mathrm{~min}$. When slices were perfused with $44 \mathrm{~mm} \mathrm{~K}^{+}$, the $\mathrm{NaCl}$ concentration of the Krebs solution was adjusted to maintain osmolarity. The calcium dependence of the dorsal root stimulation-evoked and peptide-evoked amino acid efflux was investigated by the removal of calcium ions from the Krebs solution. Statistical significance has been assessed relative to control conditions by use of either a paired or unpaired Student's $t$ test, as appropriate. Levels of significance are indicated as follows: ${ }^{*} p<0.01 ;{ }^{* *} p<0.005$.

Thirteen rats of both sexes taken from 2 different litters were injected subcutaneously with $50 \mathrm{mg} / \mathrm{kg}$ capsaicin (Sigma) in vehicle $[10 \%$ ethanol, $10 \%$ Tween $(\mathrm{vol} / \mathrm{vol})$ in $0.9 \%$ (wt/vol) saline] $48 \mathrm{hr}$ after birth. Eight control littermates received equal volumes of vehicle alone. After a survival time of $23-45 \mathrm{~d}$, the animals were subjected to the experimental procedure described above.

For SP and CGRP immunohistochemistry, lumbar spinal cords from vehicle-injected and capsaicin-treated rats were fixed with Zamboni's fixative. Serial, $50-\mu \mathrm{m}$-thick transverse sections were cut through the spinal cord with a Vibratome. These sections were then processed for SP- or CGRP-like immunoreactivity with the Sternberger's peroxidaseantiperoxidase (PAP) method and commercially available SP (Incstar Corp.) or CGRP (Peninsula Labs.) antisera at a dilution of 1:7000 and 1:3000, respectively. Details of the PAP procedure have been published (Coffield et al., 1986). Following the PAP incubation, the sections were incubated for 7-10 $\mathrm{min}$ in $0.05 \% 3,3^{\prime}$-diaminobenzidine hydrochloride (DAB, Sigma) in 0.1 м PBS and 0.01 м hydrogen peroxide $\left(\mathrm{H}_{2} \mathrm{O}_{2}\right)$ to obtain the specific immunorcactive label distinguished by a reddishbrown chromogen. The DAB-reacted sections were mounted on gelatincoated slides, dehydrated in ethanol, cleared in xylene, and coverslipped with Permount for light microscopic analysis. As a control for ligand specificity, spinal cord sections were processed without the addition of primary antisera. In this case, no immunoreactivity was seen.

\section{Results}

Basal release of endogenous amino acids from spinal dorsal horn slices

The efflux of 9 endogenous amino acids-Asp, Glu, Asn, Gln, Gly, GABA, Ser, Thr, and Ala - from the spinal cord slices into the Krebs perfusion-medium occurred, and the mean basal amino acid concentrations in the spinal cord slice perfusate are presented in Table 1 . The 9 amino acids studied are the most prominent ones to be detected in the spinal slice perfusate. The amount of Gln released was the highest, at least 5-6 times that of the next 3 relatively abundant amino acids, Ala, Gly, and Ser. Glu, GABA, and Thr were present in moderate amounts, whereas lower levels of Asp and Asn were found (Table 1).

No significant differences in the basal release of 9 endogenous 
Table 1. Amino acid concentrations in the perfusate of the horizontal spinal cord slices $(\mu \mathrm{M} / 5 \mathrm{~min}$ collection period)

\begin{tabular}{llll} 
Amino acid & $\begin{array}{l}\text { Control } \\
(n=12)\end{array}$ & $\begin{array}{l}\text { Zero Ca } \\
(n=3)\end{array}$ & $\begin{array}{l}\text { Capsaicin } \\
(n=13)\end{array}$ \\
\hline Aspartate & $0.25 \pm 0.04$ & $0.21 \pm 0.06$ & $0.16 \pm 0.03$ \\
Glutamate & $0.51 \pm 0.09$ & $0.59 \pm 0.15$ & $0.66 \pm 0.09$ \\
Asparaginc & $0.10 \pm 0.02$ & $0.21 \pm 0.04$ & $0.16 \pm 0.03$ \\
Glutamine & $7.20 \pm 1.40$ & $5.30 \pm 2.81$ & $6.94 \pm 0.99$ \\
Glycine & $1.21 \pm 0.20$ & $1.30 \pm 0.17$ & $1.20 \pm 0.28$ \\
GABA & $0.68 \pm 0.15$ & $0.61 \pm 0.30$ & $0.92 \pm 0.15$ \\
Serine & $1.10 \pm 0.15$ & $1.09 \pm 0.21$ & $1.39 \pm 0.10$ \\
Threonine & $0.60 \pm 0.07$ & $0.56 \pm 0.15$ & $0.89 \pm 0.23$ \\
Alanine & $1.29 \pm 0.27$ & $1.66 \pm 0.60$ & $1.82 \pm 0.32$ \\
\hline
\end{tabular}

Results are presented as means \pm SEM of the basal concentrations for 25 experiments conducted in duplicate. Number of observations shown in parentheses.

amino acids were detected when the spinal slices were perfused with either nominally zero $\mathrm{Ca}^{2+}$-containing medium $(n=3$; Table 1) or in those obtained from rats neonatally treated with capsaicin $(n=13$; Table 1$)$.

\section{Effects of dorsal root stimulation}

Electrical stimulation of a lumbar dorsal root produced a significant increase in the rate of basal efflux of several endogenous amino acids (Fig. 1, Table 2). Thus, in 6 different slices, highintensity repetitive stimulation $(25 \mathrm{~V}$ pulses of $20-100 \mu \mathrm{sec}$ duration applied at $3-5 \mathrm{~Hz}$ for $5 \mathrm{~min}$ ) of a lumbar dorsal root produced a significant increase in the basal release of Asp (to $160.7 \pm 9.6 \%$ ), Gln (to $143.7 \pm 9.5 \%$ ), Gly (to $130.0 \perp 9.6 \%$ ), Ser (to $145.3 \pm 14.4 \%$ ), and $\mathrm{Thr}$ (to $141.8 \pm 8.5 \%$ ), whereas the levels of Asn, Glu, GABA, and Ala were elevated only to smaller degrees (Fig. 1A). The stimulation-evoked increase in the basal release of amino acids was rarely maintained for more than one collection period of $5 \mathrm{~min}$. The higher increase in the rate of stimulation-evoked release of Asp than of Glu, and the increase in the efflux of endogenous GABA, Gly, Ser, Thr, Ala, and Asn in the spinal slice perfusate are reported here for the first time.

In order to evaluate whether the increased release of endogenous a mino acids following activation of primary afferent fibers was likely to be of neuronal origin, experiments were carried out with altered levels of $\mathrm{Ca}^{2+}$ ions in the perfusing medium. The dependence of the dorsal root electrically evoked increase in the basal release of endogenous amino acids upon the presence of $\mathrm{Ca}^{2}+$ ions in the external medium was investigatcd by pcrfusing the slices $(n=3)$ with nominally zero $\mathrm{Ca}^{2+}$ medium. The results obtained in one of those experiments are illustrated in Figure $1 B$. When $\mathrm{Ca}^{2} \cdot$ ions were omitted from the perfusing medium, the synaptic transmission was blocked and the stimulation-evoked increase in the basal release of Glu and Asp was absent (Fig. 1B, Table 2).

\section{SP and NKA modulate the basal and electrically evoked release of $G / u$ and $A s p$}

Perfusion of spinal cord slices with lower concentrations of SP $\left(2 \times 10^{7} \mathrm{M}\right.$ for $\left.5 \mathrm{~min}\right)$ caused a selective and significant increase (to $254.3 \pm 62.0 \% ; n=8$ ) in the rate of basal release of Glu (Fig. 24). With higher concentrations of SP $\left(10^{6}-5 \times 10^{-6} \mathrm{M}\right.$; $n=3$ ), in addition to Glu, a significant and dose-dependent increase in the basal release of Asp was observed (Fig. 2B). Thus,

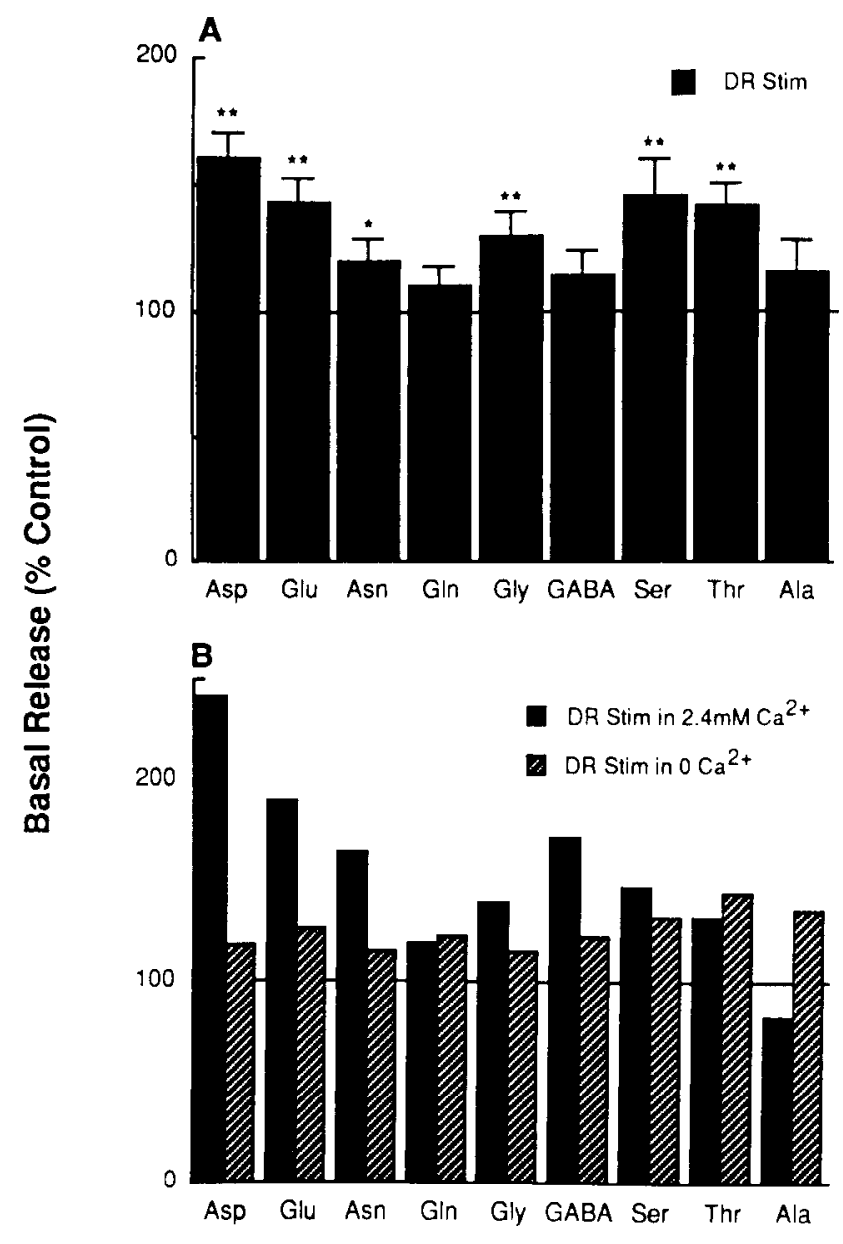

Figure 1. Effects of depolarizing stimuli and $\mathrm{Ca}^{2+}$ on the rate of basal efflux of 9 endogenous amino acids. Histogram of the release of 9 endogenous amino acids in response to electrical stimulation of a lumbar dorsal rootlet $(25 \mathrm{~V}, 0.02-0.1 \mathrm{msec}, 5 \mathrm{~Hz}, 5 \mathrm{~min})$ relative to their basal efflux determined from first 2 collection periods prior to the first period of stimulation. The results are expressed as the mean percentage of the basal efflux \pm SEM for 6 experiments conducted in duplicate. $A$. Electrical stimulation of a lumbar dorsal rootlet produced a significant increase in the concentrations of Asp (160.7 $\pm 9.6 \%)$, Glu (143.7 $\pm 9.5 \%)$. Gly $(130.0 \pm 9.6 \%)$, Ser $(145.3 \pm 14.4 \%)$, and Thr $(141.8 \pm 8.5 \%)$, whereas the levels of Asn, Gln, GABA, and Ala were elevated to a smaller degree. $B$, The stimulation-evoked increase in the basal efflux of Glu, Asp, Asn, Gly, and Ser (solid columns, $n=2$ ) was reduced or blocked in a zero-Ca ${ }^{2+}$ solution (hatched columns, $n=3$ ). Statistically significant results in this and other figures are indicated: ${ }^{* *} p<0.005$. 23- to 33-d-old rats.

for instance in a single experiment, the increase in the basal efflux of Asp elicited by $10^{\circ}$ and $5 \times 10^{\circ} \mathrm{M}$ SP amounted to 150 and $270 \%$ of their control levels, respectively. With higher concentrations of SP, the increased efflux of Glu and Asp was frequently maintained for $2-3$ consecutive 5 min collection periods. The averaged values for the SP-caused increase in the release of Glu and Asp from spinal slices are summarized in Table 2. The levels of the 7 other endogenous amino acids determined in the spinal slice perfusate were not modified in a consistent manner by SP (Fig. $2 B$ ).

The dependence of the SP-evoked increase in the release of Glu and Asp upon external $\mathrm{Ca}^{2+}$ ions was investigated by omission of this ion from the perfusing medium. When the slices ( $n$ - 3) were perfused with a nominally $\mathrm{Ca}^{2+}$-free medium, SP (5 $\left.\times 10^{-7} \mathrm{M}\right)$ still elicited a significant increase in the concentration 
A

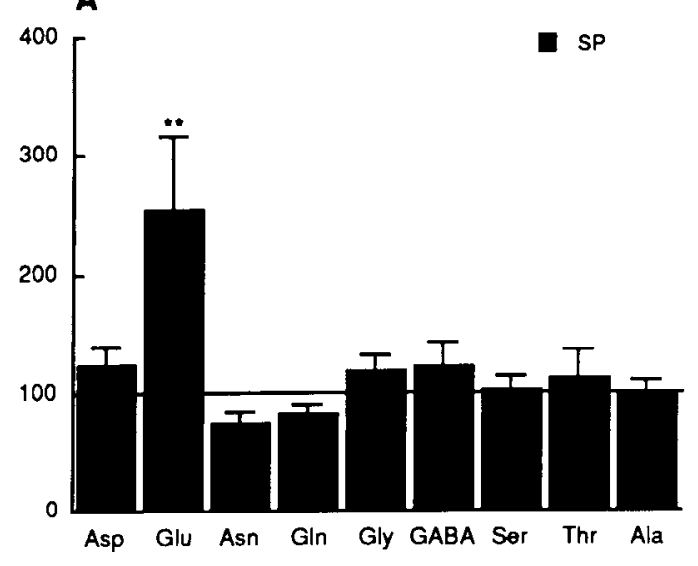

B
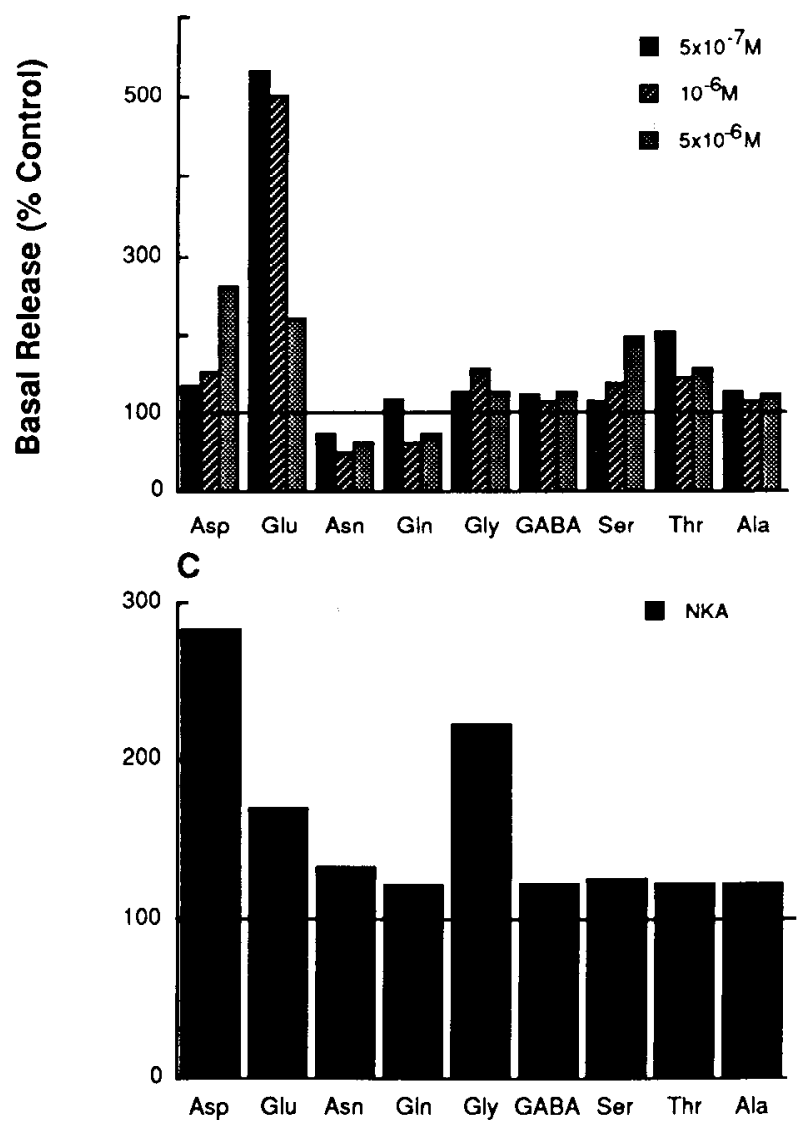

Figure 2. SP and NKA enhance the basal efflux of endogenous Glu and Asp into the spinal perfusate. $A$, Perfusion of spinal cord slices with $\mathrm{SP}\left(2-5 \times 10^{-7} \mathrm{M}\right.$ for $\left.5 \mathrm{~min}\right)$ produced a significant increase in the concentration of Glu $(254.3 \pm 62.0 \% ; n=8 ; p<0.005)$ in the perfusate, whereas the levels of other 8 amino acids were not significantly altered. $B$, Histogram of the efflux of 9 endogenous amino acids, obtained in a single experiment in response to addition of 3 different concentrations of SP to the perfusing medium: solid columns, $5 \times 10^{-7} \mathrm{M}$; hatched columns, $10^{-6} \mathrm{M}$; dotted columns, $5 \times 10^{-6} \mathrm{M}$. Bath application of SP in a concentration of $5 \times 10^{-7} \mathrm{M}$ markedly increased (533.6\%) the basal efflux of Glu only. Higher concentrations of SP $\left(10^{-6}\right.$ and $\left.5 \times 10^{-6} \mathrm{M}\right)$, in addition to Glu, caused a significant and dose-dependent increase in the basal efflux of Asp. A tendency for a decrease in the efflux of Asn and Glu was also observed. $C$, Addition of NKA $\left(10^{-6} \mathrm{M}, 5 \mathrm{~min}\right)$ to the perfusing medium produced a marked increase in the basal efflux of Asp (282.7\%), Gly (222.2\%), and Glu (170.3\%), whereas the efflux of remaining 6 amino acids was not significantly changed. $A, 24-$ to $33-\mathrm{d}$ old rats; $B, 24$-d-old rat; $C, 28$-d-old rat.

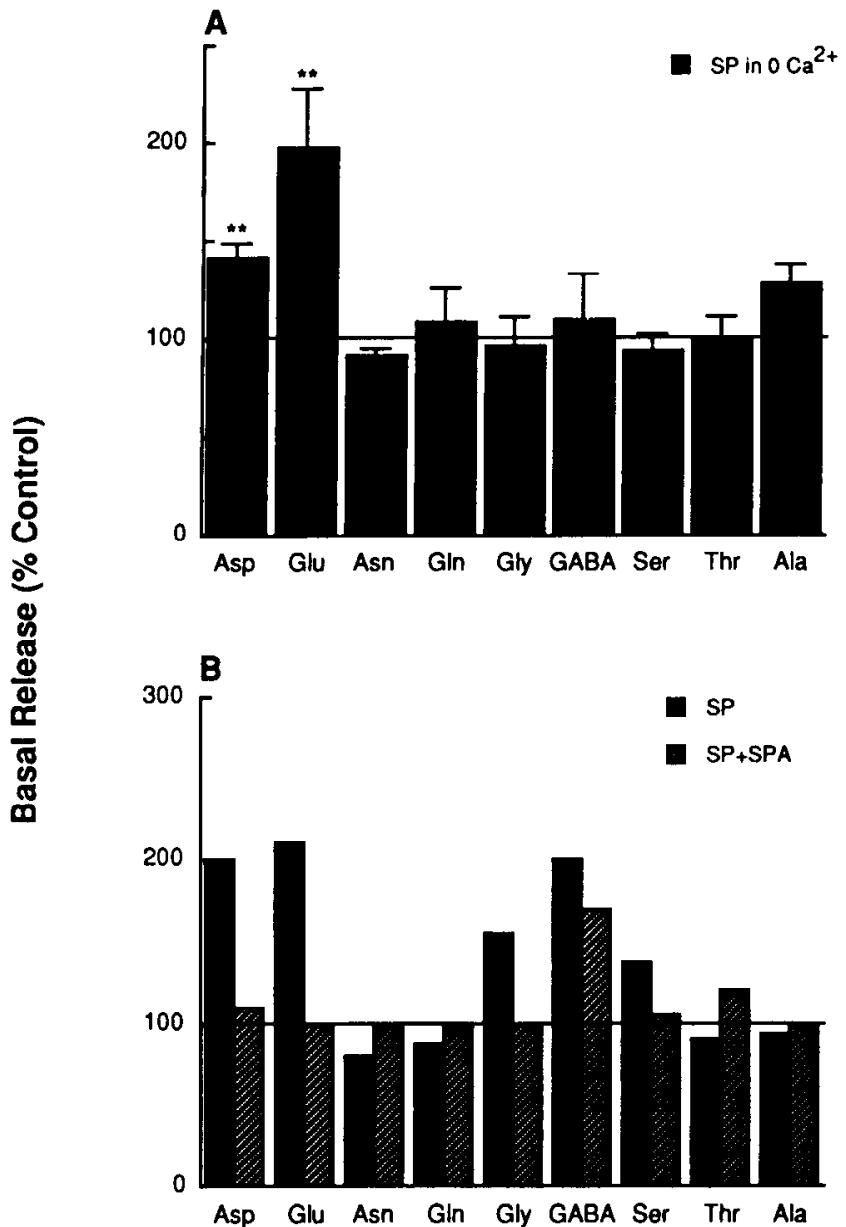

Figure 3. Enhancement of the basal efflux of Asp and Glu by SP is not $\mathrm{Ca}^{2+}$-dependent but is blocked by a claimed SP antagonist. $A$, Perfusion of the slices with nominally zero $\mathrm{Ca}^{2+}$ solution containing SP (5 $\times 10^{-7} \mathrm{M}, 5 \mathrm{~min}$ ) produced a significant increase in the concentration of Glu (198.2 $\pm 29.7 \% ; n=3)$ and Asp $(141.9 \pm 7.0 \% ; n=3)$ in the spinal perfusate. The concentrations of remaining 7 amino acids were not significantly different from the control. $B$, Perfusion of a spinal cord slice with SP $\left(5 \times 10^{-7} \mathrm{M}, 5 \mathrm{~min}\right)$ in the presence of SP antagonist, (D$\left.\mathrm{Arg}^{1}, \mathrm{D}-\mathrm{Pro}^{2}, \mathrm{D}-\mathrm{Trp}^{7.9}, \mathrm{Leu}^{11}\right)$-SP $\left(2 \times 10^{-6} \mathrm{M}, 10 \mathrm{~min}\right)$, failed to elicit an increase in the basal efflux of either Asp or Glu in the spinal perfusate (hatched columns). The data obtained during the perfusion with SP (5 $\times 10^{-7} \mathrm{M}$ ) alone are presented with the solid columns (the same slice). $A$, 26- to 33-d-old rats; $B$, 25 -d-old rat.

of Glu (to $198.2 \pm 29.7 \%$ ) in all 3 slices examined, whereas the Asp increase (to $141.9 \pm 7.0 \%$ ) was present in 2 out of 3 slices (Fig. 3A, Table 2). The persistence of the SP effect did not appear to be a consequence of an inadequate removal of extracellular $\mathrm{Ca}^{2+}$ since the dorsal root-stimulation-evoked release of Glu and Asp was virtually abolished by the removal of external $\mathrm{Ca}^{2+}$ $(n=3)$.

The effect of SP $\left(5 \times 10^{-7} \mathrm{M}\right)$ was effectively blocked by an SP analog (D-Arg' $\left.{ }^{1}, \mathrm{D}-\mathrm{Pro}^{2}, \mathrm{D}^{-} \mathrm{Trp}^{7,9}, \mathrm{Leu}^{11}\right)-\mathrm{SP}\left(2 \times 10^{-5} \mathrm{M}\right)$, a claimed antagonist of synthetic SP (Fig. $3 B$ ). This finding suggests that the effect of SP on the basal efflux of Glu is a true tachykinin receptor-mediated response.

The possibility that NKA, a SP-related tachykinin that is coexpressed with SP in primary sensory neurons (Dalsgaard et al., 1985), may regulate primary afferent transmission by mod- 
A
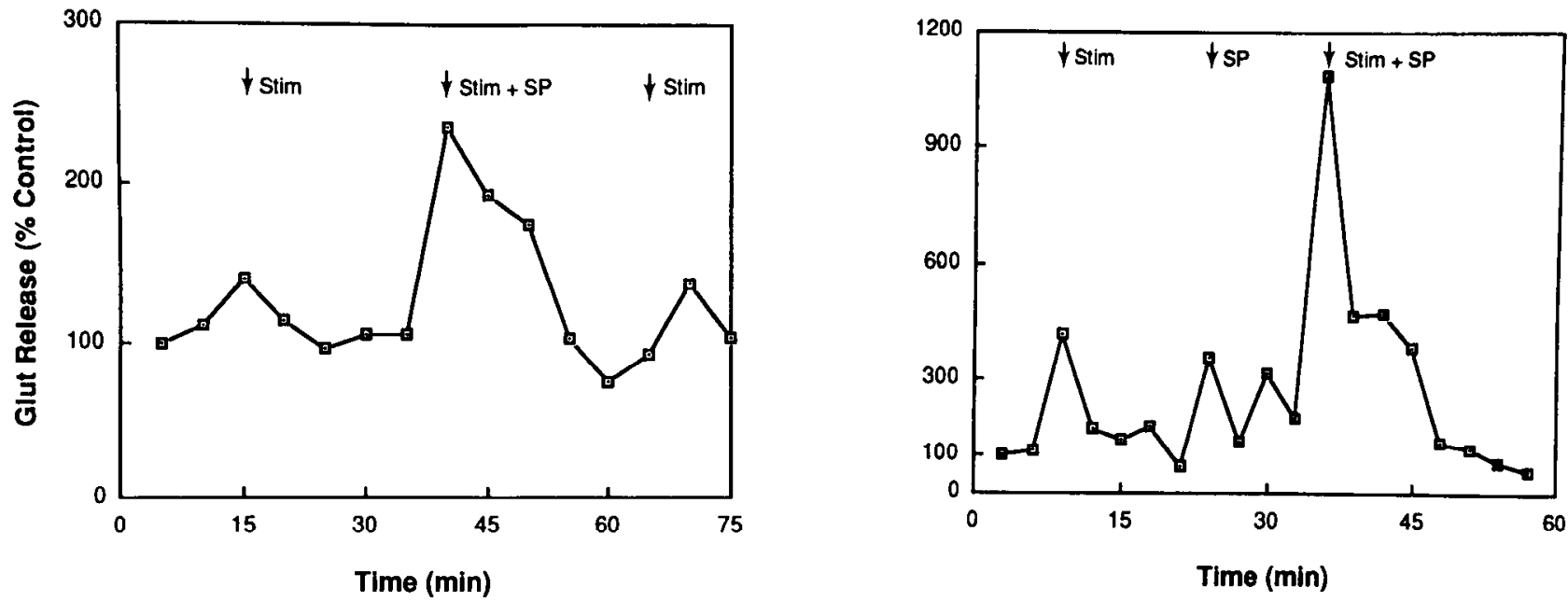

$\mathrm{B}$
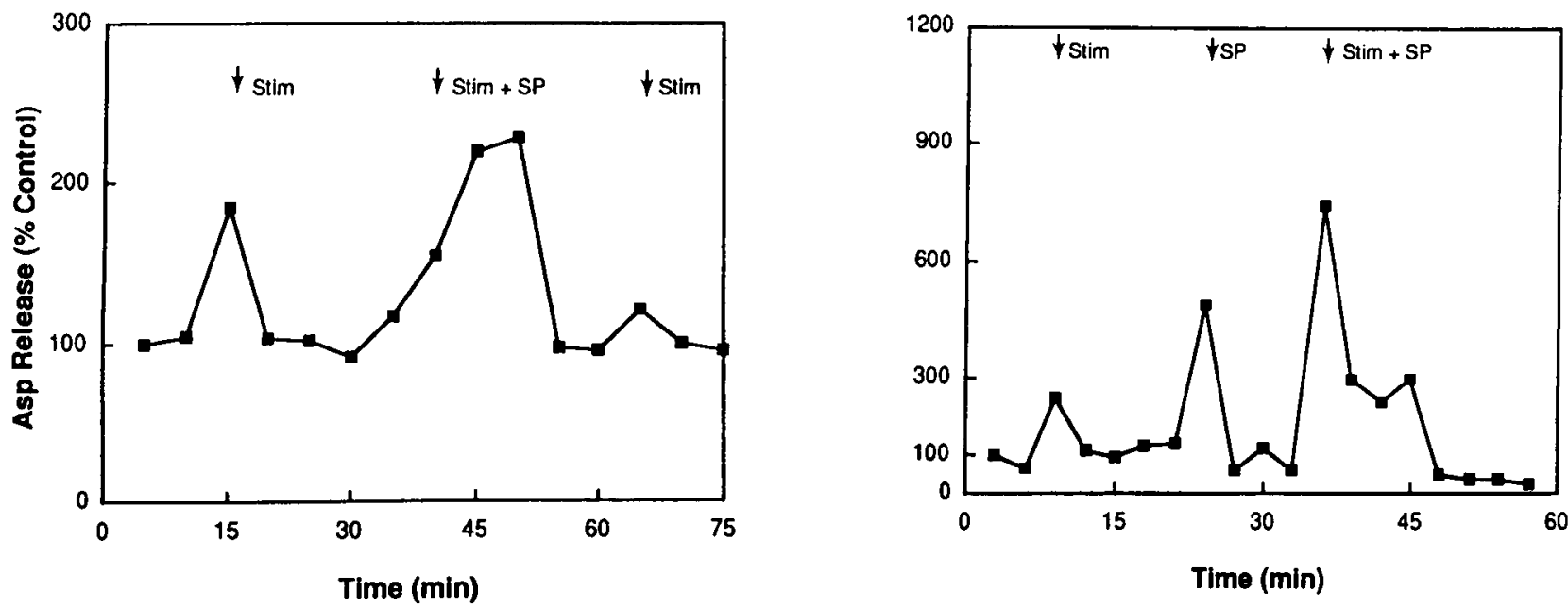

Figure 4. SP potentiates the dorsal root stimulation-evoked efflux of endogenous Glu and Asp. Interaction between the dorsal root stimulationand the SP-evoked release of Glu and Asp was studied by using 2 different protocols $(A$ and $B)$. Left panels, Three periods of electrical stimulation $(25 \mathrm{~V}, 0.02 \mathrm{msec}, 5 \mathrm{~Hz}$ for $5 \mathrm{~min}$; onset of stimulation marked by arrowheads) were applied. During the first and the third periods, the slice was perfused with a control Krebs solution, while during the second period, SP $\left(5 \times 10^{-7} \mathrm{M}\right)$ was added to the perfusate. SP increased the electrically evoked efflux of Glu from 141 to $236 \%(A)$ and that of Asp from 185 to $228 \%(B)$ of the basal value. Characteristically, the peptide prolonged the duration of the electrically evoked efflux of the amino acids from 5 to $15 \mathrm{~min}$. 29-d-old rat. Right panels, Electrical stimulation of the dorsal rootlet $(30 \mathrm{~V}, 1 \mathrm{msec}, 0.5 \mathrm{~Hz}$ for $3 \mathrm{~min}$ ) produced about a 4 -fold increase in the basal release of Glu $(A)$ and about a 2.5 -fold increase in Asp $(B)$. Addition of SP $\left(5 \times 10^{-7} \mathrm{M}\right.$ for $\left.3 \mathrm{~min}\right)$ to the perfusing medium produced a similar increase in Glu (359\%) and somewhat higher release of Asp (485\%). However, the electrical stimulation of the primary afferents in the presence of SP resulted in a higher increase in the basal cfflux of Glu (to $1091 \%$ of the basal release) and Asp (to 743\%) during the first collection period if compared to the effects of either treatment alone. The SP-enhanced efflux of Glu and Asp lasted about 12 min. 27-d-old rat.

ulating the basal release of Glu and Asp was investigated in 5 spinal slices. As shown in a single experiment illustrated in Figure $2 C$. NKA $\left(10^{-6} \mathrm{M}\right)$ produced a marked increase in the rate of basal efflux of Asp (to 282.7\%), Gly (to 222.2\%), and Glu (to $170.3 \%$ ), whereas the efflux of the remaining 6 amino acids was not significantly altered. The summary of the effects of NKA $\left(5 \times 10^{-7}\right.$ to $\left.10^{-6} \mathrm{M}\right)$ on the basal efflux of Glu and Asp is presented in Table 2 .

Moreover, we sought to determine whether, besides modulating the basal release, SP also modulates the dorsal root stim- ulation-evoked release of Glu and Asp from the spinal slices. Thus, in 4 slices, the release during a stimulation period was compared with that measured during exposure of a spinal slice to SP $\left(10^{-7}-10^{-6} \mathrm{M}\right)$ and electrical stimulation of a lumbar dorsal root. We found that in the presence of SP, the electrically stimulated release of Glu (Fig. 4A) and Asp (Fig. 4B), was potentiated. Characteristically, unlike the response to electrical stimulation that was usually limited to the first collection period, the SP-evoked response was prolonged, lasting 10-15 min after the first exposure to the peptide (Fig. 4). 


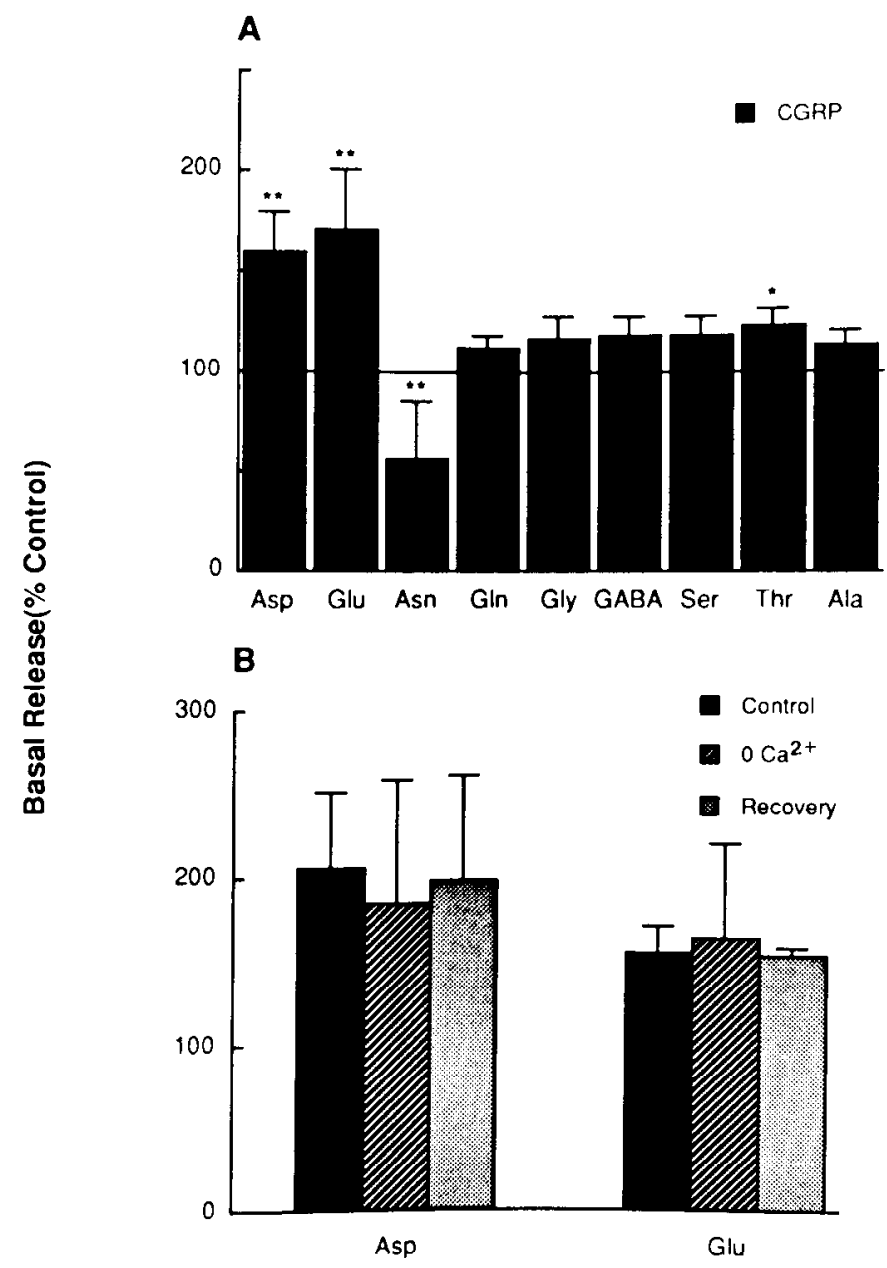

Figure 5. A, CGRP enhanced the basal efflux of Asp and Glu into the perfusate of spinal slices. Perfusion of spinal cord slices with CGRP $\left(10^{-7} \mathrm{M}\right)$ produced a significant increase in the concentration of Glu (to $170.5 \pm 30.6 \%$ ) and Asp (to $159.5 \pm 20.1 \%$ ) and a decrease in Asn (to $56.2 \pm 29.2 \%$ ), whereas the levels of the remaining 6 amino acids were not markedly changed. The results are expressed as mean percentages of the basal efflux \pm SEM for 4 experiments. $B$, In 3 experiments the CGRP-evoked increase in the basal efflux of Asp and Glu (solid columns, before; dotted columns, after returning to $2 \mathrm{mM} \mathrm{Ca}^{2+}$ medium) was not significantly altered when the slices were perfused with a nominally zero $\mathrm{Ca}^{2+}$ medium (hatched columns). 27- to 31-d-old rats.
rCGRP modulates the basal and electrically evoked release of Glu and Asp

We found that rat calcitonin gene-related peptide (rCGRP, $10^{-7}$ M) caused a significant increase in the basal efflux of Glu (to $170.5 \pm 30.6 ; n=4$ ) and Asp (to $159.5 \pm 20.1 ; n=4$ ), and a smaller increase in $\mathrm{Thr}$ (Fig. $5 A$ ). In addition, there was a significant decrease in the basal release of Asn, whereas the levels of 5 other endogenous amino acids were increased only to a small degree. In contrast to the immediate elevation of Glu and Asp in response to electrical stimulation of primary afferents, the CGRP-caused increase of the basal release was delayed, frequently reaching a maximum $10 \mathrm{~min}$ after the first exposure of the slice to the peptide. At the second exposure to the same concentration of CGRP, the CGRP effect was reduced, indicating the occurrence of desensitization.

When calcium was removed from the perfusing medium, the CGRP-evoked enhancement of the basal release of Glu occurred in 2 out of 4 slices examined, whereas the increase in Asp was present, although reduced in magnitude, in 3 out of 4 slices. The average of 3 experiments where the effects of CGRP were tested in nominally zero $\mathrm{Ca}^{2+}$ medium is presented in Figure $5 B$.

We have recently shown that CGRP enhances calcium currents of rat dorsal root ganglion neurons and spinal excitatory synaptic transmission (Ryu et al., 1988a). As Ca $\mathrm{Ca}^{2+}$ influx is intimately related to neurotransmitter release, a similar action of CGRP on voltage-sensitive $\mathrm{Ca}^{2+}$ channels at central terminals of primary sensory neurons, as shown for the somatic membrane of DRG neurons (Ryu et al., 1988a), could increase neurotransmitter release and facilitate excitatory synaptic transmission. In support of this hypothesis, we found that in the presence of CGRP $\left(10^{-7} \mathrm{M}\right)$ the electrically elicited release of Glu (Fig. $6 \mathrm{~A}$ ) and Asp (Fig. 6B) was increased. The CGRP-evoked response was prolonged, lasting about $30 \mathrm{~min}$, and was oscillatory in character.

Effects of neonatal capsaicin treatment on the dorsal root-and peptide-evoked release of endogenous amino acids

The question of whether the enhanced release of Glu and Asp following electrical stimulation of dorsal roots and administration of SP, NKA, and CGRP reflects direct release from activated primary afferent fibers (axons and/or presynaptic endings) in the dorsal horn or whether it could reflect activation of sec-

\begin{tabular}{|c|c|c|c|c|c|c|}
\hline & \multicolumn{3}{|l|}{ Control } & \multicolumn{3}{|l|}{ Capsaicin } \\
\hline & Asp & Glu & $n$ & Asp & Glu & $n$ \\
\hline \multicolumn{7}{|l|}{ A. Electrical stimulation } \\
\hline Normal Krebs & $209.2 \pm 26.7$ & $168.3 \pm 14.0$ & (13) & $109.8 \pm 14.2$ & $109.6 \pm 14.8$ & 7 \\
\hline Zero $\mathrm{Ca}^{2+}$ solution & $94.7 \pm 10.9$ & $101.4 \pm 7.8$ & (3) & - & - & \\
\hline \multicolumn{7}{|l|}{ B. Peptides } \\
\hline $\mathrm{SP}\left(2-5 \times 10^{-7} \mathrm{M}\right)$ & $123.2 \pm 15.3$ & $254.3 \pm 62.0$ & (8) & $113.6 \pm 18.7$ & $104.9 \pm 19.0$ & 6 \\
\hline $\mathrm{SP}\left(1-5 \times 10^{-6} \mathrm{M}\right)$ & $181.7 \pm 40.1$ & $339.3 \pm 84.2$ & (3) & - & - & \\
\hline $\mathrm{SP}\left(5 \times 10^{-7} \mathrm{M}\right.$ in $\left.0 \mathrm{Ca}^{2+}\right)$ & $141.9 \pm 7.0$ & $198.2 \pm 29.7$ & (3) & - & - & \\
\hline $\operatorname{NKA}\left(5 \times 10^{-7}\right.$ to $\left.10^{-6} \mathbf{M}\right)$ & $179.1 \pm 35.1$ & $145.3 \pm 16.1$ & (5) & - & - & \\
\hline $\operatorname{CGRP}\left(10^{-7} \mathbf{M}\right)$ & $159.5 \pm 20.1$ & $170.5 \pm 30.6$ & (4) & $161.2 \pm 15.0$ & $138.8 \pm 13.4$ & 4 \\
\hline
\end{tabular}

Results are presented as mean percentages \pm SEM of the basal efflux. Dorsal root stimulation: $25-30 \mathrm{~V}, 0.02-1.0 \mathrm{msec}, 3-10 \mathrm{~Hz}$ for $5 \mathrm{~min}$. Number of observations shown in parentheses ( $n$ represents the number of slices; each slice was obtained from a different animal). 

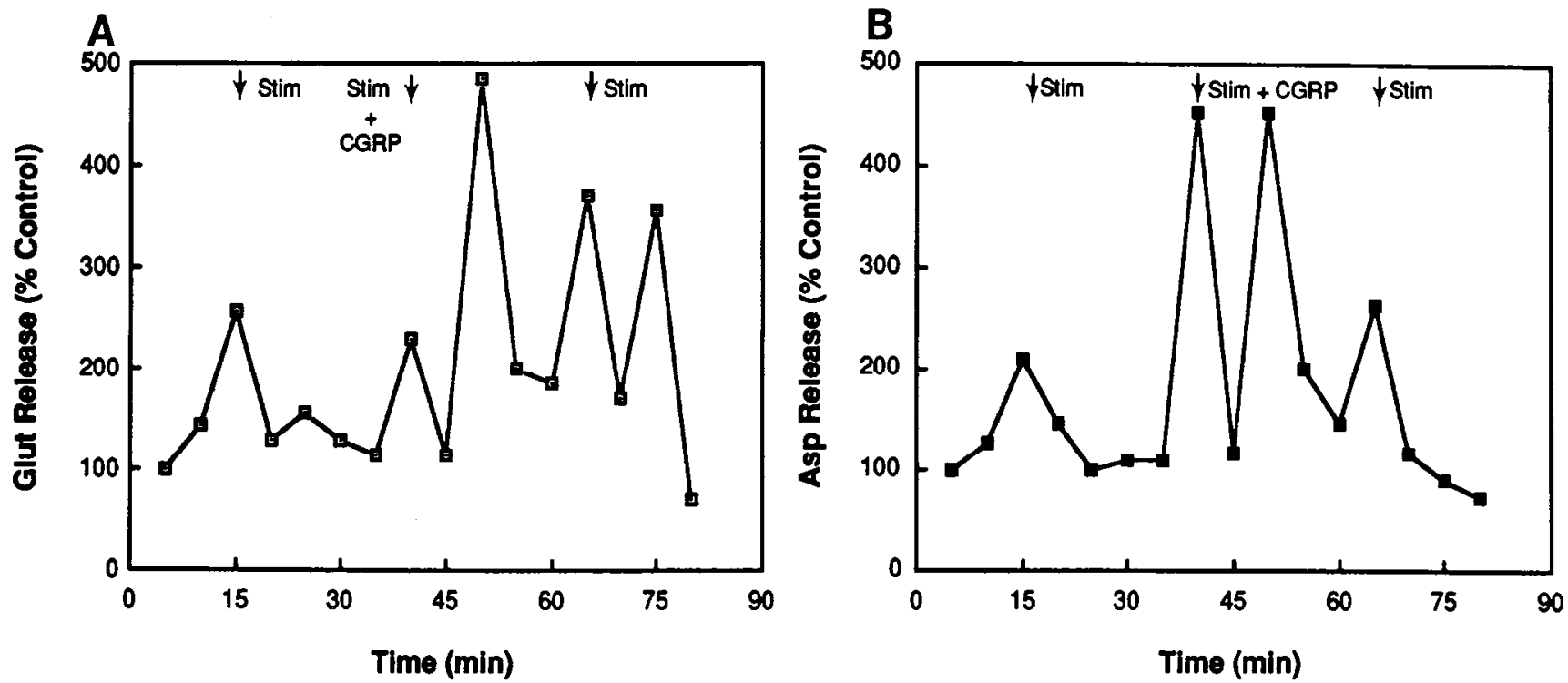

Figure 6. CGRP enhances the dorsal root stimulation-evoked efflux of endogenous Glu and Asp. $A$, Bath addition of CGRP (10 ${ }^{-7} \mathrm{M}$ for 5 min) increased the electrically ( $25 \mathrm{~V}, 0.1 \mathrm{msec}, 5 \mathrm{~Hz}$ for $5 \mathrm{~min}$ ) evoked efflux of Glu from about 257 to $486 \%$ relative to control. Characteristically, the incrcase in the releasc oscillated and the oscillations lastcd about $30 \mathrm{~min}$. B, In the same slice, CGRP also increased the efflux of Asp from 209 to $456 \%$ of control. As with Glu, the release was oscillatory in character and of prolonged duration. 29-d-old rat.

ondary or tertiary cells in the primary afferent-dorsal horn neuronal pathways was investigated in slices obtained from capsaicin-treated rats. If capsaicin were to prevent the enhancement of the stimulation-evoked and peptide-evoked basal release of Glu and Asp, it is likely that a significant proportion of released amino acids would arise from sensory endings sensitive to capsaicin.

Although in the present study we found that neonatal capsaicin treatment did not markedly alter the basal efflux of 9 endogenous amino acids from the spinal slices, it prevented the dorsal root stimulation-evoked release of endogenous amino acids (Fig. 7). The stimulation-enhanced efflux of Asp, Glu, Asn, Gly, and Thr seen in vehicle-injected control animals $(n=8)$ was significantly reduced in the slices obtained from the capsaicin-treated rats ( $n=13$; Fig. 7, Table 2$)$.

The effects of neonatal capsaicin treatment on the SP- and CGRP-enhanced basal efflux of Glu and Asp from the spinal slices of rats killed at 3-6 weeks of age are shown in Figures 8 and 9 and Table 2 . The results obtained show that neonatal capsaicin treatment prevented the SP-induced increase in the concentration of Glu in the spinal perfusate (Fig. 8). This result suggests that intact unmyelinated $(\mathrm{C})$ and perhaps small myelinated $(\mathrm{A} \delta$ ) primary afferent fibers may be an important source of released Glu following dorsal root stimulation or SP administration. In contrast to the SP-effect, the CGRP-induced increase in the basal levels of Glu and Asp was not prevented in the slices obtained from the capsaicin-treated rats (Fig. 9). It is of interest, however, that CGRP-caused reduction of the basal release of Asn seen in the vehicle-treated animals appears to be abolished by capsaicin treatment. The blockade of the SP effect on Glu release seen in the capsaicin-treated rats suggests that the peptide may regulate the release of the excitatory neurotransmitters by acting at presynaptic sites. On the other side, the persistence of the effect of CGRP in the capsaicin-treated rats may reflect the prevalent effect of CGRP on the release of Glu and Asp from the interneurons or descending afferents to the dorsal horn. However, since there is significant CGRP staining left after capsaicin treatment (Fig. 9, $A, B$; see also Diez
Guerra et al., 1988), this finding may imply that subcutaneous treatment with capsaicin is not effective in eliminating all the CGRP-LI primary afferent input.

\section{Discussion}

Dorsal root stimulation-evoked release of endogenous amino acids and the effects of capsaicin

The findings of the present study confirm previous reports that dorsal root stimulation evokes a $\mathrm{Ca}^{2+}$-dependent release of $\mathrm{Glu}$

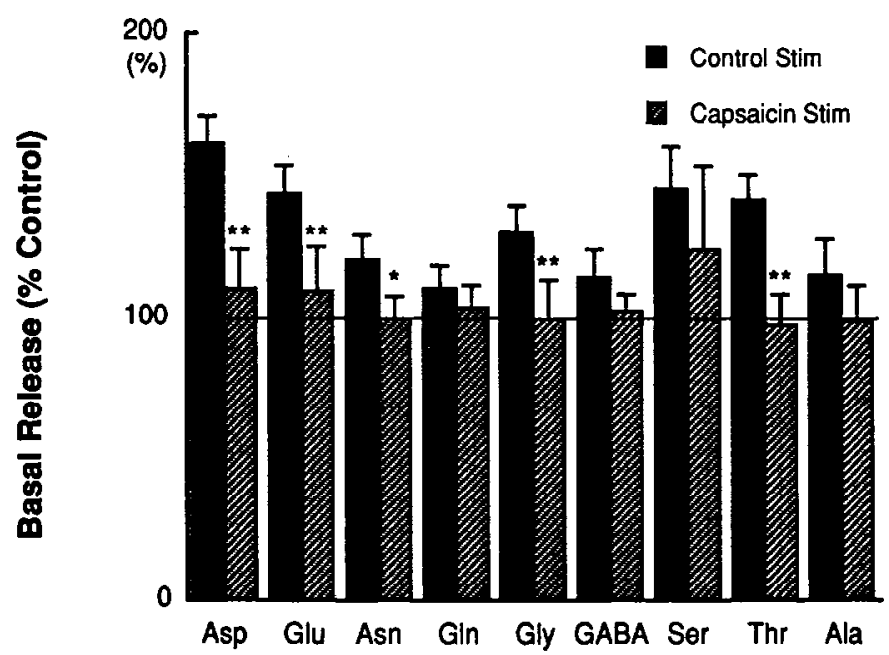

Figure 7. Neonatally applied capsaicin reduced the dorsal root stimulation-evoked release of Asp and Glu. The dorsal root stimulationevoked increase in the release of endogenous Asp, Glu, Gly, and Thr from the horizontal spinal cord slices of intact rats (solid columns) was absent in the slices obtained from the rats treated neonatally with capsaicin (hatched columns). Rats were allowed to survive 3-6 weeks after injection of Tween $80 / \mathrm{ethanol} / \mathrm{saline}(1: 1: 8)$ vehicle or vehicle containing $50 \mathrm{mg} / \mathrm{kg}$ capsaicin. The results for control $(n=6)$ and capsaicin $(n=7)$ groups are expressed as mean percentages \pm SEM of the respective basal values. Statistical difference between the release in intact and capsaicin-treated rats: ${ }^{* *} p<0.005,{ }^{*} p<0.01 .23$ - to 45 -d-old rats. 
A

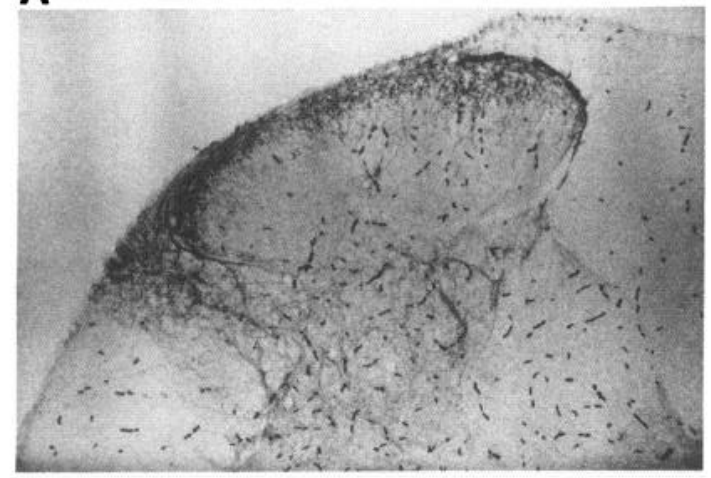

B

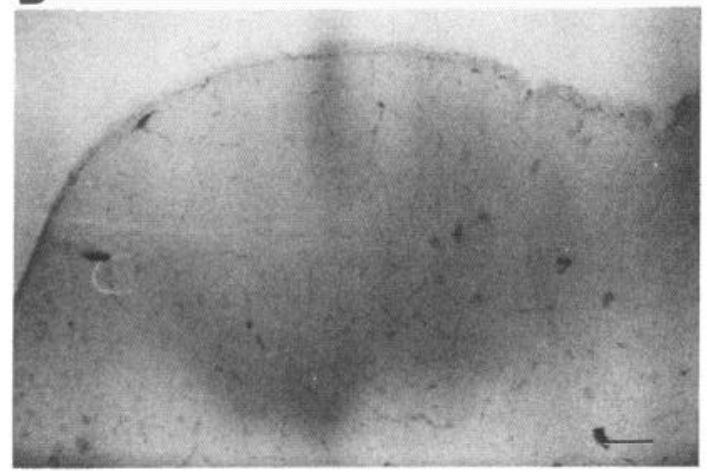

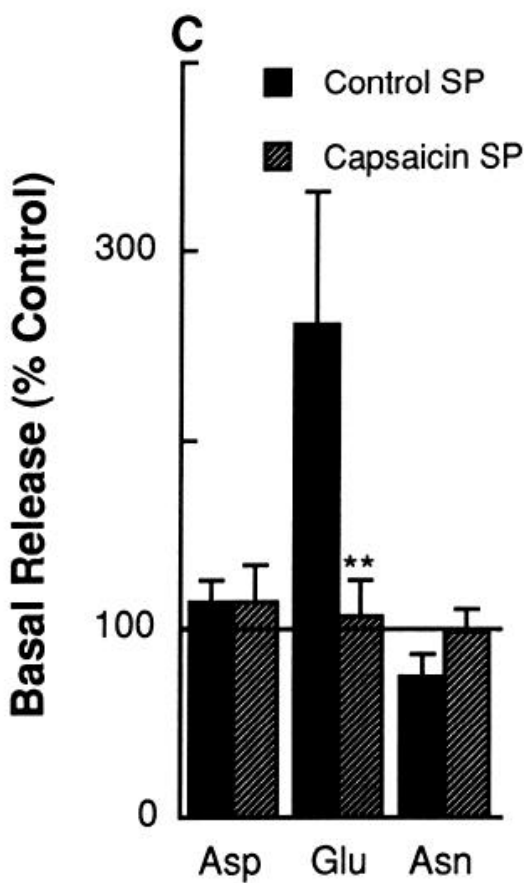

Figure 8. Immunoperoxidase staining of the rat lumbar spinal cord for SP$\mathrm{LI}$ in rats injected with control vehicle $(A)$ and rats treated with capsaicin neonatally $(B)$. Scale bar, $100 \mu \mathrm{M}$. $C$, The SP-induced increase in the basal efflux of endogenous Glu from the spinal cord slices of the intact rats (solid columns) was absent in the rats treated with capsaicin neonatally (hatched columns). The results for control $(n=7)$ and capsaicintreated animals $(n=6)$ are presented as mean percentages \pm SEM of their respective basal values. Statistical difference between the release in the intact and capsaicin-treated rats: ${ }^{* *} p<0.005$. 24- to 44-d-old rats.
A

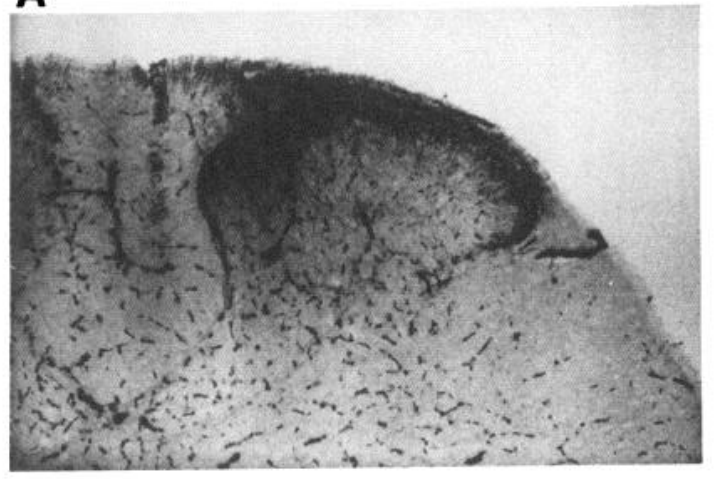

B

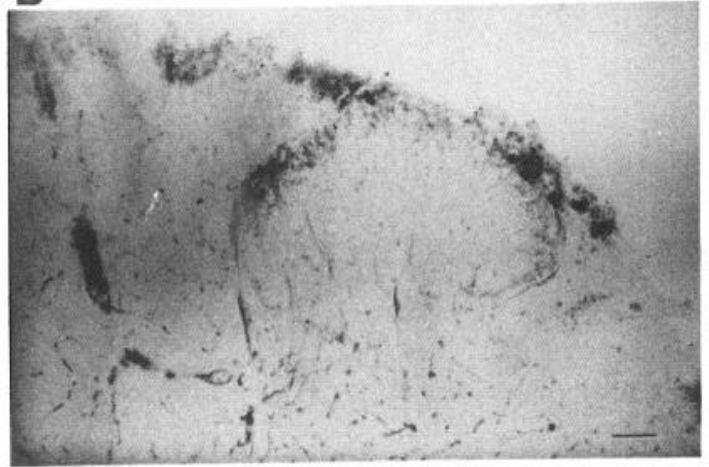

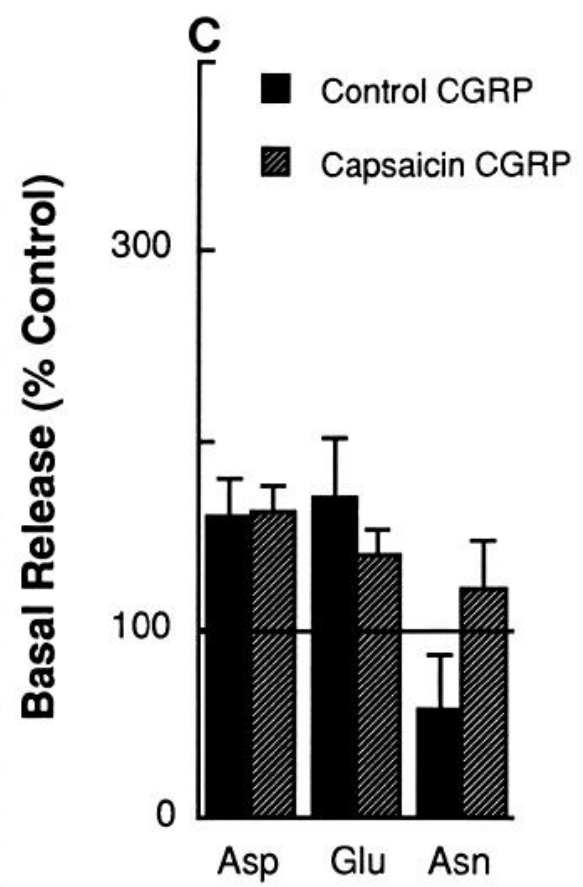

Figure 9. Immunoperoxidase staining of the rat lumbar spinal cord for CGRP-LI in rats injected with control vehicle $(A)$ and rats treated with capsaicin neonatally $(B)$. Scale bar, $100 \mu \mathrm{M}$. $C$, The CGRP-elicited increase in the basal efflux of endogenous Glu and Asp from the spinal cord slices of intact rats (solid columns) was present in rats treated with capsaicin neonatally (hatched columns). The results in control $(n=4)$ and capsaicin-treated rats $(n=4)$ are presented as mean percentages of their respective controls \pm SEM. 27- to 45-d-old rats. 
from the frog (Takcuchi ct al., 1983) and the ncwborn rat spinal cord in vitro (Kawagoe et al., 1986). These earlier studies also examined the evoked release of Asp and found it to be less regularly observed than for Glu and statistically insignificant. On the basis of these observations, the suggestion was made that Glu is the principal transmitter released by dorsal root stimulation (Kawagoe et al., 1986). The results from this study clearly show that besides Glu, several endogenous amino acids, including Asp, Asn, Gly, Ser, and Thr are released in significantly higher amounts upon high-intensity repetitive electrical stimulation of primary afferent fibers. It is worth noting that despite our finding that the basal efflux of Asp is only about half that of Glu, the stimulation-evoked increase in the basal release of Asp appears to be similar, or even higher, than that of Glu. Two observations indicate that the electrically evoked release of Asp does not result from nonspecific changes in permeability of neuronal membranes. First, the release of Asp was repeatable, and, following stimulation, baseline levels of released Asp completely recovered to control levels. Second, the release was blocked by perfusing solution containing zero $\mathrm{Ca}^{2+}$. This is as expected for a process of calcium-dependent exocytosis. We would like to suggest, therefore, that the stimulation-evoked release of Asp is likely to be relevant for excitatory neurotransmission in the spinal dorsal horn. This suggestion is in agreement with a recent demonstration of Asp-immunoreactive axons in normal rat L4 dorsal roots (Westlund et al., 1989b). Although it is well known that L-Glu acts as a mixed agonist at both NMDA and non-NMDA excitatory amino acid receptors (Mayer and Westbrook, 1984), L-Asp appears to be selective for NMDA receptors (Watkins, 1981; Mayer and Westbrook, 1984). Several recent in vitro studies, using either brain slices or isolated spinal cord preparations, have demonstrated that NMDA receptors can be activated during monosynaptic and polysynaptic transmission (Dale and Roberts, 1985; Forsythe and Westbrook, 1988; Gerber and Randic, 1989a).

As shown in Figure $1 A$, electrical stimulation of dorsal roots also resulted in significant increases in the concentrations of Gly and Ser in the spinal perfusate. This finding may have functional implications for spinal excitatory synaptic transmission and intcgration of sensory information incoming to the dorsal horn since it has been shown that responses of spinal neurons to the excitatory amino acid NMDA are markedly potentiated by nanomolar concentrations of Gly (Johnson and Ascher, 1987). This, together with the demonstration that the strychnine-insensitive Gly binding site is distinct from, but associated with, the NMDA receptor (Bonhaus and McNamara, 1988) has initiated considerable interest in Gly as a modulator of NMDA-receptor-mediated synaptic transmission (Salt, 1989; Thomson et al., 1989). Although the mechanisms by which Gly acts on NMDA receptors are not well understood (Danysz et al., 1989), Mayer et al. (1989) have recently presented evidence indicating that at least part of the enhancement of NMDA response by Gly occurs through acceleration of recovery from desensitization. D-Ser (a Gly analog) is able to substitute for Gly in preventing desensitization (Mayer et al., 1989). In this context, it is noteworthy that we have recently observed that the responses of rat dorsal horn neurons, either acutely isolated (Murase et al., 1989b) or some in the spinal slice (Gerber et al., 1989), to NMDA are augmented by $10^{-7}-10^{-6} \mathrm{M}$ Gly.

It has been shown that, besides the primary afferent fibers (Wheeler et al., 1966; Roberts, 1974; Takeuchi et al., 1983; Kawagoe et al., 1986), some descending pathways in the dorsal horn (Stonc, 1979; Rustioni and Cucnod, 1982; Potashner and Tran, 1985; Potashner and Dymzyk, 1986) and some intrinsic dorsal horn interneurons (Davidoff et al., 1967; Rustioni and Cuenod, 1982) may use Glu as a neurotransmitter. Therefore, the question of whether a proportion of the released Glu and Asp following electrical stimulation of primary afferent fibers derives from activation of primary sensory neurons or whether it could reflect activation of secondary or tertiary cells in the dorsal horn pathways cannot be satisfactorily addressed by the experiments discussed above. In order to investigate the contribution of primary sensory neuronal Glu and Asp pools to the stimulation-evoked release of these amino acids, we used neonatal treatment of rats with capsaicin, a neurotoxin known to cause degeneration of a large number of small "dark" sensory neurons (Jancso et al., 1977; Nagy et al., 1981). In this study, we show that capsaicin prevents the stimulation-evoked release of Glu, Asp, Gly, and Thr, the results suggesting a possibility that a significant proportion of the release of these endogenous amino acids is likely to arise from primary afferent fibers sensitive to capsaicin. Our finding of capsaicin sensitivity of the stimulation-evoked Glu release is in agreement with recent morphological data indicating that Glu is preferentially localized in a subpopulation of small dorsal root ganglion cells (Cangro et al., 1985; Battaglia et al., 1987), unmyelinated dorsal root axons (Westlund et al., 1989a), and synaptic terminals in the superficial laminae of the spinal cord of rats, many of which are likely to represent endings of unmyelinated $(\mathrm{C})$ or small myelinated $(\mathrm{A} \delta$ ) fibers (DeBiasi and Rustioni, 1988). Thus, the morphological data and the results of the capsaicin release experiments reported in this work lend further support to the hypothesis that Glu and/or Asp is likely to be involved in the first-order transmission of cutaneous information, particularly from $\mathrm{C}$ and $\mathrm{A} \delta$ primary afferents (Schneider and Perl, 1985).

\section{Enhancement of the basal and the dorsal root stimulation-evoked release of endogenous Glu and Asp by SP, NKA, and CGRP}

The results of the experiments reported here demonstrate that tachykinins (SP and NKA) and CGRP induce an apparently specific, predominantly $\mathrm{Ca}^{2+}$-independent increase in the basal release of putative primary afferent transmitters, Glu and Asp. Although the enhancing and selective effect of SP on the release of endogenous Glu from the hemisected spinal cord of newborn rats, first observed by Kawagoe et al. (1986), has been confirmed, the different results were obtained in regard to the magnitude of the SP effect, its $\mathrm{Ca}^{2+}$ dependence, and the dose-related, SPinduced release of Asp. Kawagoe et al. (1986) found that the bath application of SP (5-10 $\mu \mathrm{M})$ caused an average increase in the basal release of Glu of about $130 \%$, the magnitude of the effect being comparable to the effect of dorsal root stimulation. The Asp release induced by SP was small and statistically insignificant. In addition, they found that the release of Glu, but not of Asp, was decreased or abolished in the perfusing medium containing low concentrations of $\mathrm{Ca}^{2+}$ or TTX. In contrast to the results of Kawagoe et al. (1986), we found that perfusion of spinal cord slices with lower concentrations of SP $\left(10^{-7} \mathrm{M}\right)$ was accompanied by a selective and marked (2- to 3-fold) increase in the rate of basal efflux of Glu. With higher concentrations of SP $\left(10^{-6} \mathrm{M}\right)$, however, the basal release of Asp was also augmented in a dose-dependent manner. The SP-caused increase in the release of Glu was consistently larger than that produced by the dorsal root stimulation, and the effect could be demon- 
strated in the absence of external $\mathrm{Ca}^{2+}$. The inconsistencies between our results and those of Kawagoe et al. (1986) may be ascribed to methodological differences presented by their use of glucose-free perfusing solution, an amino acid uptake blocker ( $\alpha$-methyl Asp), and the newborn-rat hemisected spinal cord preparation.

In relation to the results discussed above, it is noteworthy that Smullin et al. (1988), using dorsal horn dialysis probe in freely moving rats, observed a higher increase in endogenous Asp than in Glu in response to $1 \mathrm{~mm}$ SP administration, and no increase in the basal concentration of Asp, Glu, Gly, and laurine upon administration of $10 \mu \mathrm{M}$ CGRP.

The data in Figure $2 C$ show that an SP-related tachykinin, NKA, which occurs in primary sensory neurons, and in an even higher concentration than SP in the rat spinal dorsal horn (Kanazawa et al., 1984; Brodin et al., 1986), also increases the basal release of Glu, Asp, and Gly from the rat spinal slices. Although in a few experiments the relative potencies of SP and NKA with respect to the stimulation of the basal release of Asp and Glu appear to be similar, in 8 experiments SP appeared to increase the release of Glu more, whereas NKA preferentially increased the basal release of Asp $(n=5)$. Since NKA also exhibits a potent excitatory action on spinal neurons that is depressed by an SP antagonist (D-Arg', D-Pro', D-Trp ${ }^{7.9}$, Leu ${ }^{11}$ )-SP, it is likely that some of the physiological roles that have been attributed to SP in sensory neurotransmission are, in fact, mediated by NKA, or both tachykinins.

The origin of the excitatory amino acids that are released and the mechanism(s) underlying the enhancement of the release of Glu and Asp by tachykinins and CGRP have yet to be elucidated. In the present study, we have demonstrated that in contrast to the electrically evoked release of Glu and Asp from the spinal slice, which does not occur when $\mathrm{Ca}^{2+}$ is absent from the external medium, the enhancement of the basal release of the amino acids by SP and CGRP appears to be, in a large part, $\mathrm{Ca}^{2+}$ independent. Since the $\mathrm{Ca}^{2+}$ independence of the releasing action of peptide receptors seems to exclude the involvement of $\mathrm{Ca}^{2+}$-mediated exocytosis, it is possible that peptide ligandinduced neurotransmitter release may be mediated by secondmessenger systems rather than depolarization-induced calcium influx. There is evidence for the role of protein kinase C (Nishizuka, 1984; Nichols et al., 1987; Gerber et al., 1989) and the cyclic AMP system in neurotransmitter (Nestler and Greengard, 1983) and peptide release. In addition, it is of interest that CCK-8 evokes secretion of oxytocin and vasopressin from rat neural lobe, independent of external calcium, and that the CCK-8 action is blocked by an inhibitor of protein kinase C (Bondy et al., 1989). On the other hand, SP is known to increase hydrolysis of phosphoinositides in central neurons (Watson and Downes, 1983), whereas some actions of CGRP are thought to be mediated through activation of adenylate cyclase (Crossman et al., 1987; Wang and Fiscus, 1989). Two experimental results are relevant for the possible second-messenger mediation of the enhancement of the release of Glu by SP. First, Womack et al. (1988) have shown that in about one-third of cultured dorsal horn neurons, SP receptor activation increases cytosolic free $\mathrm{Ca}^{2+}$ via mobilization of intracellular $\mathrm{Ca}^{2+}$ stores, and a suggestion was made that the intracellular pathway for the action of SP may involve the generation of inositol phosphate intermediates. Second, we have recently demonstrated (Gerber et al., 1989) that perfusion of rat spinal slices with phorbol esters, the agents known to activate the calcium- and phospholipid-dependent protein kinase C (Nishizuka, 1984, 1986), produces an increase in the basal and electrically evoked release of endogenous excitatory (glutamic, aspartic) and inhibitory amino acids (GABA, Gly).

Besides the neuronal source (axons and/or nerve terminals), the peptide-caused increase in the basal release of Glu and Asp from the glial cells should also be considered. The extracellular microenvironment of the central neurons is largely bounded by glial membranes, and glial cells have been postulated to influence the concentration of neurotransmitters in the synaptic cleft by a variety of mechanisms. Evidence exists that amino acids are relcascd by high- $\mathrm{K}^{+}$solution in a $\mathrm{Ca}^{2+}$-independent manner (Drejer et al., 1982, 1983) and that astrocytes may be intimately involved in neurotransmission processes, amino acid uptake (Hertz and Schousboe, 1986; Hösli et al., 1986), and they possess receptors for amino acid transmitters (Glu, Asp, GABA) and peptides (Bowman and Kimelberg, 1984; Kettermann and Schachner, 1985; Hamprecht, 1986; Torrens et al., 1986). Binding sites for SP were detected on glial cells of the spinal cord and SP enhances accummulation of labeled inositol phosphates in cultures of cortical glial cells from the mouse (Torrens et al., 1986). In addition, synthetic human calcitonin raises intracellullar concentration of cyclic AMP in rat astroglia cells (Hamprecht, 1986).

It is well established that the principal mode of inactivation of putative excitatory (Glu, Asp) and inhibitory (GABA, Gly) neurotransmitters released from nerve endings is by reuptake, using high-affinity ion- and membrane potential-dependent transport systems that are known to operate both in neuronal and glial membranes (Fonnum, 1984; Hösli et al., 1986). Thus, another potential mechanism for the enhancement of the basal release of Glu and of Asp by tachykinins and CGRP is via the electrogenic transport system, which is $\mathrm{Ca}^{2+}$ independent and would be expected to "release" Glu and Asp whenever cells are depolarized. It is of interest that the Gly uptakc systcm is inhibited by the peptides, leu- and met-enkephalin (Rhoads et al., 1984).

It is well established that the release of classical neurotransmitters is controlled by autoreceptors, heteroreceptors, or receptors that are acted upon by co-localized substances, such as neuropeptides (Chesselet, 1984; Bartfai et al., 1988) and that this mechanism plays an important role in determining the amount of transmitter released per each stimulus. It was first demonstrated in the example of $\mathrm{ACh} /$ vasointestinal polypeptide (VIP) coexistence in the postganglionic neurons of the cat that muscarinic cholinergic autoreceptors inhibit the release of both $\mathrm{ACh}$ and VIP. VIP, on the other hand, enhanced the release of $\mathrm{ACh}$ (Lundberg et al., 1980). VIP enhancement of ACh-evoked salivation in the cat submandibular gland (Lundberg et al., 1980) was followed by demonstration of synergistic effects of ACh and VIP in promoting phosphatidylinositol turnover in the cerebral cortex, i.e., at the sites of coexistence of ACh and VIP. Synergistic effects of 5-HT, TRH, and SP in the ventral spinal cord have also been observed (Iverfeldt et al., 1986; Tremblay et al., 1986).

The finding that Glu and SP coexist in primary afferent terminals in the superficial laminae of the rat spinal dorsal horn (DeBiasi and Rustioni, 1988), coupled with the demonstrated potentiation of the basal and stimulation-evoked efflux of Glu and Asp by SP and NKA in this study, provide evidence for a role of tachykinins in the regulation of Glu and Asp release. Thus, in addition to the excitatory postsynaptic actions of tachy- 
kinins on the dorsal horn neurons (Murase and Randic, 1984; Murase et al., 1989a, b) and modulation of the $\mathrm{Ca}^{2+}$ conductances (Ryu and Randic, 1990), the tachykinins may also serve some important presynaptic function through the regulation of the release of coexisting primary afferent transmitters. It would seem that excitatory co-release of amino acids and tachykinins could serve to interact cooperatively to result in a potentiation of depolarizing action at postsynaptic sites on dorsal horn neurons. These pre- and postsynaptic mechanisms of action of tachykinins, and other sensory peptides, may have important physiological implications for strengthening the synaptic connections in the spinal dorsal horn. Such a dual role is consistent with our present knowledge about multiple pre- and postsynaptic actions of peptides in the PNS (Lundberg et al., 1980).

\section{References}

Barber RP, Vaughn JE, Slemmon JR, Salvaterra PM, Roberts E, Leeman SE (1979) The origin, distribution and synaptic relationships of substance $P$ axons in rat spinal cord. J Comp Neurol 184:331-352.

Bartfai T, Iverfeldt K, Fisone G, Serfozo P (1988) Regulation of the release of coexisting neurotransmitters. Annu Rev Pharmacol Toxicol $28: 285-310$

Battaglia G, Rustioni A, Altschuler RA, Petrusz P (1987) Glutamic acid coexists with substance $P$ in some primary sensory neurons. In: Fine afferent fibers and pain (Schmidt RF, Schaible H-G, Vahle-Hinz C, eds), pp 77-84. Weinheim: VCH Publishers.

Bondy CA, Jensen RT, Brady LS, Gainer H (1989) Cholecystokinin evokes secretion of oxytocin and vasopressin from rat neural lobe independent of external calcium. Proc Natl Acad Sci USA 86:51985201

Bonhaus DW, McNamara JO (1988) N-methyl-D-aspartate receptor regulation of uncompetitive antagonist binding in rat brain membranes: kinetic analysis. Mol Pharmacol 34:250-255.

Bowman C, Kimelberg H (1984) Excitatory amino acids directly depolarize rat brain astrocytes in primary culture. Nature 311:656-659.

Brodin E, Lindefors N, Dalsgaard C-J, Theodorsson-Norheim E, Rosel $S$ (1986) Tachykinin multiplicity in rat central nervous system as studied using antisera raised against substance $\mathrm{P}$ and neurokinin $\mathrm{A}$ Regulat Peptides 13:253-272.

Brodin E, Linderoth B, Gazelius B, Ungerstedt M (1987) In vivo release of substance $P$ in cat dorsal horn studied with microdialysis. Neurosci Lett 76:357-362.

Cangro CB, Sweetnam PM, Wrathall JR, Haser WB, Curthoys NP, Neale JH (1985) Localization of elevated glutaminase immunoreactivity in small DRG neurons. Brain Res 336:158-161.

Chesselet M-F (1984) Presynaptic regulation of neurotransmitter release in the brain. Facts and hypothesis. Neuroscience 12:347-375.

Coffield JA, Miletic V, Zimmermann E, Hoffert MJ, Brooks BR (1986) Demonstration of thyrotropin-releasing hormone immunoreactivity in neurons of the mouse spinal dorsal horn. J Neurosci 6:1 194-1197.

Crossman D, McEwan J., MacDermot J, Macintyre I, Dollery CT (1987) Human calcitonin gene-related peptide activates adenylate cyclase and releases prostacyclin from human umbilical vein endothelial cells. Br J Pharmacol 92:695-701.

Curtis DR, Phillis JW, Watkins JC (1960) The chemical excitation of spinal neurones by certain acidic amino acids. J Physiol (Lond) 150: 656-682.

Dale N, Roberts A (1985) Dual-component amino acid-mediated synaptic potentials: excitatory drive for swimming in Xenopus embryos. J Physiol (Lond) 363:35-59.

Dalsgaard C-J, Hagerstrand A, Theodorsson-Norheim E, Brodin E, Hökfelt T (1985) Neurokinin A-like immunoreactivity in rat primary sensory neurons; coexistence with substance $P$. Histochemistry 83:37-39.

Danysz W, Wroblewski JT, Brooker G, Costa E (1989) Modulation of glutamate receptors by phencyclidine and glycine in the rat cerebellum: cGMP increase in vivo. Brain Res 479:270-276.

Davidoff RA, Graham LT, Shank RP, Werman R, Aprison MH (1967) Changes in amino acid concentrations associated with loss of spinal interneurons. J Neurochem 14:1025-1031.
DeBiasi S, Rustioni A (1988) Glutamate and substance $P$ coexist in primary afferent terminals in the superficial laminae of spinal cord. Proc Natl Acad Sci USA 85:7820-7824.

Diez Guerra FJ, Zaidi M, Bevis P, MacIntyre I, Emson PC (1988) Evidence for release of calcitonin gene-related peptide and neurokinin A from sensory nerve endings in vivo. Neuroscience 25:839-846.

Drejer J, Larsson OM, Schousboe A (1982) Characterization of L-glutamate uptake into and release from astrocytes and neurons cultured from different brain regions. Exp Brain Res 47:259-269.

Drejer J, Larsson OM, Schousboe A (1983) Characterization of uptake and release processes for $\mathrm{D}$ - and L-aspartate in primary cultures of astrocytes and cerebellar granule cells. Neurochem Res 8:231-243.

Fonnum F (1984) Glutamate: a neurotransmitter in mammalian brain J Neurochem 42:1-11.

Forsythe ID, Westbrook GL (1988) Slow excitatory postsynaptic currents mediated by N-methyl-D-aspartate receptors on cultured mouse central neurones. J Physiol (Lond) 396:515-533.

Franco-Cereceda A, Henke H, Lundberg JM, Petermann JB, Hökfelt T, Fischer JA (1987) Calcitonin gene-related peptide (CGRP) in capsaicin-sensitive substance $\mathrm{P}$-immunoreactive sensory neurons in animals and man: distribution and release by capsaicin. Peptides 8 : $399-410$.

Galindo A, Krnjevic K, Schwartz S (1967) Micro-iontophoretic studies on neurones in the cuneate nucleus. J Physiol (Lond) 192:359377.

Gamse R, Molnar R, Lembeck F (1979) Substance P release from spinal cord slices by capsaicin. Life Sci 25:629-636.

Gerber G, Randic M (1989a) Excitatory amino acid-mediated components of synaptically evoked input from dorsal roots to deep dorsal horn neurons in the rat spinal cord slice. Neurosci Lett 106:211-219.

Gerber G, Randic M (1989b) Participation of excitatory amino acid receptors in the slow excitatory synaptic transmission in the rat spinal dorsal horn in vitro. Neurosci Lett 106:220-228.

Gerber G, Kangrga I, Ryu PD, Larew JSA, Randic M (1989) Multiple effects of phorbol esters in the rat spinal dorsal horn. J Neurosci 9: 3606-3617.

Gibson SJ, Polak JM, Bloom SR, Sabate IM, Mulderry PM, Ghatei MA, McGregor GP, Morrison JFB, Kelly JS, Evans RM, Rosenfeld MG (1984) Calcitonin gene-related peptide immunoreactivity in the spinal cord of man and eight other species. J Neurosci 4:3101-3111.

Greenamyre JT, Young AB, Penney JB (1984) Quantitative autoradiographic distribution of $\mathrm{L}\left[{ }^{3} \mathrm{H}\right]$ glutamate-binding sites in rat central nervous system. J Neurosci 4:2133-2144.

Hamprecht B (1986) Astroglia cells in culture: receptors and cyclic nucleotides. In: Astrocytes (Fedoroff S, Vernadakis A, eds), pp 77106, Vol 2. New York: Academic.

Henke H, Tschopp FA, Fischer JA (1985) Distinct binding sites for calcitonin gene-related peptide and salmon calcitonin in rat central nervous system. Brain Res 360:165-171.

Henry JL, Krnjevic K, Morris ME (1975) Substance P and spinal neurons. Can J Physiol Pharmacol 53:423-434.

Hertz L, Schousboe A (1986) Role of astrocytes in compartmentation of amino acids and energy metabolism. In: Astrocytes (Fedoroff S Vernadakis A, eds), pp 179-209, Vol 2. New York: Academic.

Hökfelt T, Kellerth JO, Nilsson G, Pernow B (1975) Substance P localization in the central nervous system and in some primary sensory neurons. Science 190:889-890.

Hösli E, Hösli L, Schousboe A (1986) Amino acid uptake. In: Astrocytes (Fedoroff S, Vernadakis A, eds), Vol 2, pp 133-153. New York: Academic.

Hua X-Y, Saria A, Gamse R, Theodorsson-Norheim E, Brodin E, Lundberg JM (1986) Capsaicin-induced release of multiple tachykinins (substance P, neurokinin A and eledoisin-like material) from guineapig spinal cord and ureter. Neuroscience 19:313-320.

Iverfeldt K, Peterson L-L, Brodin E, Ogren SO, Bartfai T (1986) Serotonin type- 2 receptor mediated regulation of substance $P$ release in the ventral spinal cord and the effects of chronic antidepressant treatment. Naunyn-Schmiedeberg's Arch Pharmacol 333:1-6.

Jancso G, Kiraly E, Jancso-Gabor A (1977) Pharmacologically induced selective degeneration of chemosensitive primary sensory neurons. Nature 270:741-743.

Johnson JW, Ascher P (1987) Glycine potentiates the NMDA response in cultured mouse brain neurons. Nature 325:529-531.

Kanazawa I, Ogawa T, Kimura S, Munekata E (1984) Regional dis- 
tribution of substance $P$, neurokinin $\alpha$ and neurokinin $\beta$ in rat central nervous system. Neurosci Res 2:111-120.

Kangrga I, Gerber G, Randic M (1988) N-methyl-D-aspartate receptor mediated component of fast and slow excitatory synaptic transmission in the rat spinal dorsal horn. Soc Neurosci Abstr 14:96.

Kangrga I, Larew JSA, Randic M (1989) SP and CGRP modulate basal and evoked release of glutamate and aspartate from the rat spinal dorsal horn. Soc Neurosci Abstr 15:227.

Kangrga I, Larcw JSA, Randic M (1990) The effects of substance P and calcitonin gene-related peptide on the efflux of endogenous glutamate and aspartate from the rat spinal dorsal horn in vitro. Neurosci Lett 108:155-160.

Kawagoe R, Onodera K, Takeuchi A (1986) The release of endogenous glutamate from the newborn rat spinal cord induced by dorsal root stimulation and substance P. Biomed Res 7:253-259.

Kettermann H, Schachner M (1985) Pharmacological properties of GABA, glutamate and aspartate induced depolarizations in cultured astrocytes. J Neurosci 5:3295-3301.

Lindroth P, Mopper V (1979) High performance liquid chromatographic determination of subpicomole amounts of amino acids by precolumn fluorescence derivatization with $o$-phthaldialdehyde. Anal Chem 51:1667-1674.

Lundberg JM, Anggard A, Fahrenkrug J, Hökfelt T, Mutt V (1980) Vasoactive intestinal polypeptide in cholinergic neurons of exocrine glands. Functional significance of co-existing transmitters for vasodilatation and secretion. Proc Natl Acad Sci USA 77:1651-1655.

Mantyh PW, Hunt SP, Maggio JE (1984a) Substance P receptors: localization by light microscopic autoradiography in rat brain using [ $\left.{ }^{3} \mathrm{H}\right] \mathrm{SP}$ as the radioligand. Brain Res 307:147-165.

Mantyh PW, Pinnock RD, Downes CP, Goedert M, Hunt SP (1984b) Correlation betwen inositol phospholipid hydrolysis and substance $\mathrm{P}$ receptors in rat central nervous system. Nature 309:795-797.

Mayer ML, Westbrook GL (1984) Mixed agonist action of excitatory amino acids on mouse spinal cord neurones under voltage clamp. J Physiol (Lond) 354:29-53.

Mayer ML, Westbrook GL (1987) The physiology of excitatory amino acids in the vertebrate central nervous system. Prog Neurobiol 28: 197-276.

Mayer ML, Vyklicky L Jr, Clements J (1989) Regulation of NMDA receptor desensitization in mouse hippocampal neurons by glycine. Nature 338:425-427.

Monaghan DT, Cotman CW (1985) Distribution of N-methyl-D-aspartate-sensitive L- $\left[{ }^{3} \mathrm{H}\right]$ glutamate-binding sites in rat brain. J Neurosci 5:2909-2919.

Murase K, Randic M (1983) Electrophysiological properties of rat spinal dorsal horn neurones in vitro: calcium dependent action potentials. J Physiol (Lond) 334:141-154.

Murase K, Randic M (1984) Actions of substance P on rat spinal dorsal horn neurones. J Physiol (Lond) 346:203-217.

Murase K, Ryu PD, Randic M (1989a) Tachykinins modulate multiple ionic conductances in voltage clamped rat spinal dorsal horn neurons. J Neurophysiol 61:854-865.

Murase K, Ryu PD, Randic M (1989b) Excitatory and inhibitory amino acids and peptide-induced responses in acutely isolated rat spinal dorsal horn neurons. Neurosci Lett 103:56-63.

Nagy JI, Hunt SP, Iversen LL, Emson PC (1981) Biochemical and anatomical observations on the degeneration of peptide-containing primary afferent neurons after neonatal capsaicin. Neuroscience 6: 1923-1934.

Nestler EJ, Greengard P (1983) Protein phosphorylation in the brain. Nature 305:583-588.

Nichols RA, Haycock JW, Wang JKT, Greengard P (1987) Phorbol ester enhancement of neurotransmitter release from rat brain synaptosomes. J Neurochem 48:615-621.

Nishizuka Y (1984) Turnover of inositol phospholipids and signal transduction. Science 225:1365-1370.

Nishizuka Y (1986) Studies and prospectives on protein kinasc C. Science 223:308-312.

Otsuka M, KonishiS (1976) Release of SP-like immunoreactivity from isolated spinal cord of newborn rat. Nature 264:83-84.

Potashner SJ, Dymzyk L (1986) Amino acid levels in the guinea pig spinal gray matter after axotomy of primary sensory and descending tracts. J Neurochem 47:412-422.

Potashner SJ, Tran PL (1985) Decreased uptake and release of
D-aspartate in the guinea pig spinal cord after partial cordotomy. J Neurochem 44:1511-1519.

Randic M, Miletic V (1977) Effects of substance P in cat dorsal horn neurones activated by noxious stimuli. Brain Res 128:164-169.

Randic M, Ryu PD, Urban L (1986) Effects of polyclonal and monoclonal antibodies to substance $P$ on slow excitatory transmission in rat spinal dorsal horn. Brain Res 383:15-27.

Rhoads DE, Peterson NA, Raghupathy E (1984) Iminoglycine transport system in synaptosomes and its interaction with enkephalins. Biochemistry 23:117-121.

Roberts PJ (1974) The release of amino acids with proposed neurotransmitter function from the cuneate and gracile nuclei of the rat in vivo. Brain Res 67:419-428.

Roberts PJ, Mitchell JF (1972) The release of amino acids from the hemisected spinal cord during stimulation. J Neurochem 19:24732481.

Rustioni A, Cuenod M (1982) Selective retrograde transport of $D$-aspartate in spinal interneurons and cortical neurons of rats. Brain Res 236:143-155.

Ryu PD, Randic M (1990) Low- and high-voltage-activated calcium currents in rat spinal dorsal horn neurons. J Neurophysiol 63:273285.

Ryu PD, Gerber G, Murase K, Randic M (1988a) Calcitonin generelated peptide enhances calcium current and spinal excitatory synaptic transmission. Neurosci Lett 89:305-312.

Ryu PD, Gerber G, Murase K, Randic M (1988b) Actions of calcitonin gene-related peptide on rat dorsal horn neurons. Brain Res 441:357361 .

Salt TE (1989) Modulation of NMDA receptor-mediated responses by glycine and D-serine in the rat thalamus in vivo. Brain Res 481 $403-406$

Salt TE, Hill RG (1983) Neurotransmitter candidates of somatosensory primary afferent fibers. Neuroscience 10:1083-1 103.

Saria A, Gamse R, Petermann J, Fischer JA, Theordorsson-Norheim E, Lundberg JM (1986) Simultaneous release of several tachykinins and calcitonin gene-related peptide from rat spinal cord. Neurosci Lett 63:310-314.

Schneider SP, Perl ER (1985) Selective excitation of neurons in the mammalian spinal cord by aspartate and glutamate in vitro: correlation with location and excitatory input. Brain Res 360:339-343.

Smullin DH, Skilling SR, Larson AA (1988) Substance P-induced release of excitatory amino acids from the spinal cord of freely moving rats monitored by microdialysis. Soc Neurosci Abstr 14:873.

Stone TW (1979) Amino acids as neurotransmitters of corticofugal neurons in rat: a comparison of glutamate and aspartate. Br J Pharmacol 67:545-551.

Takeuchi A, Onodera K, Kawagoe R (1983) The effects of dorsal root stimulation on the release of endogenous glutamate from the frog spinal cord. Proc Jpn Acad B 59:88-92.

Thomson AM, Walker VE, Flynn DM (1989) Glycine enhances NMDA-receptor mediated synaptic potentials in neocortical slices. Nature 338:422-424.

Torrens Y, Beaujouan JC, Saffroy M, Daguet de Montety MC, Bergstrom L, Glowinski J (1986) Substance P receptors in primary cultures of cortical astrocytes from the mouse. Proc Natl Acad Sci USA 83:9216-9220.

Tremblay LE, Maheux R, Bedard PJ (1986) Substance P in the lumbar spinal cord of the rat affects the motor response to 5-HTP and TRH. Neuropharmacology 25:419-424.

Urban L, Randic M (1984) Slow excitatory transmission in rat dorsal horn: possible mediation by peptides. Brain Res 290:336-341.

Wanaka A, Shiotani Y, Kiyama H, Matsuama T, Kamada T, Shiosaka S, Tohyama M (1987) Glutamate-like immunoreactive structures in primary sensory neurons in the rat detected by a specific antiserum against glutamate. Exp Brain Res 65:691-694.

Wang X, Fiscus RR (1989) Calcitonin gene-related peptide increases cAMP, tension and rate in rat atria. Am J Physiol 256:R421-R428.

Watkins JC (1981) Pharmacology of excitatory amino acid transmitters. In: Amino acid neurotransmitters (DeFeudis FV, Mandel P, eds), pp 205-212. New York: Raven.

Watkins JC, Evans RH (1981) Excitatory amino acid transmitters. Annu Rev Pharmacol Toxicol 21:165-204.

Watson SP, Downes CP (1983) Substance P induced hydrolysis of inositol phospholipids in guinea pig ileum and rat hypothalamus. Eur J Pharmacol 93:245-253. 
Weinberg RJ, Conti F, Van Eyck SL, Petrusz P, Rustioni A (1987) Glutamate immunoreactivity in superficial laminae of rat dorsal horn and trigeminal nucleus. In: Excitatory amino acid transmission (Hicks TP, Lodge D, McLennan H, eds), pp 173-176. New York: Liss.

Westlund KN, McNeill DL, Coggeshall RE (1989a) Glutamate immunoreactivity in rat dorsal root axons. Neurosci Lett 96:13-17.

Westlund KN, McNeill DL, Patterson JT, Coggeshall RE (1989b) Aspartate immunoreactive axons in normal rat L4 dorsal roots. Brain Res 489:347-351.

Wheeler DD, Boyarski LL, Brooks WH (1966) The release of amino acids from nerve during stimulation. J Cell Physiol 67:141-148.
Womack MD, MacDermott AB, Jessell TM (1988) Sensory transmitters regulate intracellular calcium in dorsal horn neurones. Nature 334:351-353.

Yaksh TL, Jessell TM, Gamse R, Mudge AW, Leeman SF (1980) Intrathecal morphine inhibits substance $P$ release from mammalian spinal cord in vivo. Nature 286:155-157.

Zieglgänsberger W, Puil EA (1973) Actions of glutamic acid on spinal neurones. Exp Brain Res 17:35-49. 